Portland State University

PDXScholar

Summer 8-2-2016

\title{
Understanding Neighborhood Satisfaction for Individuals with Psychiatric Disabilities: a Mixed Methods Study
}

Amy Leigh Shearer

Portland State University

Follow this and additional works at: https://pdxscholar.library.pdx.edu/open_access_etds

Part of the Mental and Social Health Commons, and the Psychology Commons Let us know how access to this document benefits you.

Recommended Citation

Shearer, Amy Leigh, "Understanding Neighborhood Satisfaction for Individuals with Psychiatric Disabilities: a Mixed Methods Study" (2016). Dissertations and Theses. Paper 3119.

https://doi.org/10.15760/etd.3115

This Thesis is brought to you for free and open access. It has been accepted for inclusion in Dissertations and Theses by an authorized administrator of PDXScholar. Please contact us if we can make this document more accessible: pdxscholar@pdx.edu. 
Understanding Neighborhood Satisfaction for Individuals with Psychiatric Disabilities:

A Mixed Methods Study

by

Amy Leigh Shearer

A thesis defense submitted in partial fulfillment of the requirements for the degree of

Master of Science

in

Psychology

Thesis committee:

Greg Townley, Chair

Joel Steele

Keith Kaufman

Portland State University

2016 


\begin{abstract}
Physical and social characteristics of neighborhoods are important to resident satisfaction for clinical and nonclinical populations. This study draws upon data collected from a sample of 172 individuals with psychiatric disabilities living in 16 supportive housing sites in the Portland, Oregon metropolitan area. Research questions explore the extent to which subjective and objective measures of neighborhood physical and social environments contribute to neighborhood satisfaction for this population. Mixed methods were employed to construct a detailed understanding of the factors that influence satisfaction with one's neighborhood of residence. Predictor variables were neighborhood social climate, neighborhood physical quality, perceptions of safety, crime reports, neighborhood diversity, and WalkScore data. This study found that aspects of the social environment collectively accounted for more variance in neighborhood satisfaction than physical environmental variables; further, subjective assessments of the environment were more predictive of neighborhood satisfaction than objective indicators. Qualitative data were collected on aspects of the neighborhood that residents liked and disliked. These data were analyzed using thematic content analysis to contextualize quantitative findings. Findings provide important information regarding neighborhood features that contribute to or detract from neighborhood satisfaction among individuals with psychiatric disabilities. Supportive housing programs aiming to improve residents' wellbeing and increase residential tenure may consider looking to features of the neighborhood that most impact resident experiences.
\end{abstract}




\section{Acknowledgements}

I would like to thank my advisor, Dr. Greg Townley, for his guidance throughout the completion of this project. I would also like to thank Dr. Keith Kaufman and Dr. Joel Steele for their participation on my committee, and support and advice throughout this process. In addition, I would like to thank the staff and residents of Cascadia Behavioral Healthcare in Portland, Oregon, without whom this project would not be possible. Finally, I would like to thank my family and friends for their unwavering love, support and encouragement. 


\section{Contents}

$\begin{array}{lc}\text { Abstract } & \text { i } \\ \text { Acknowledgements } & \text { ii } \\ \text { Introduction } & 1\end{array}$

Social-ecological Perspectives ........................................................................ 5

Objective Measures versus Subjective Perceptions ................................................ 9

Study Overview 11

Resident Satisfaction......................................................................................... 12

Neighborhood Physical Environment ................................................................... 16

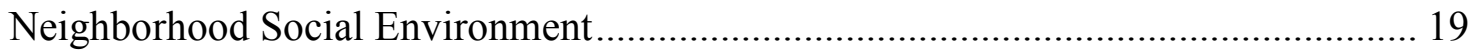

Study Purpose and Research Questions .................................................................. 24

Methods 29

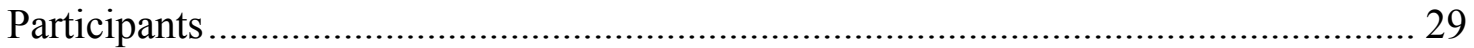

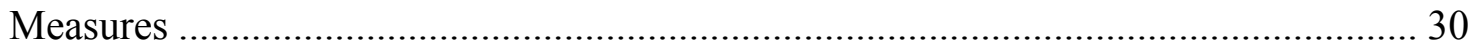

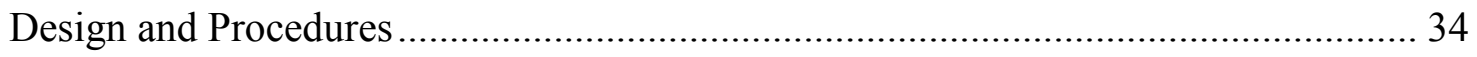

Data Analysis and Results $\quad 36$

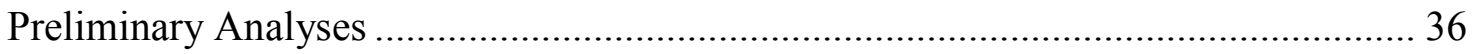

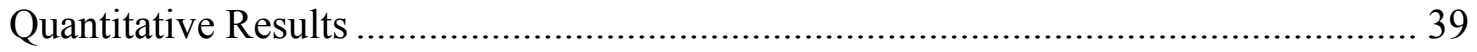

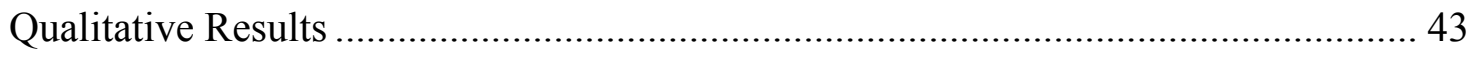

Discussion $\quad 50$

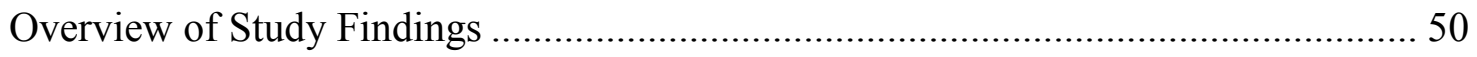


Table of Contents, continued

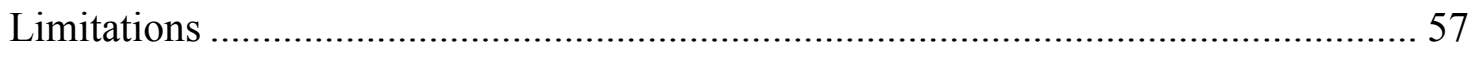

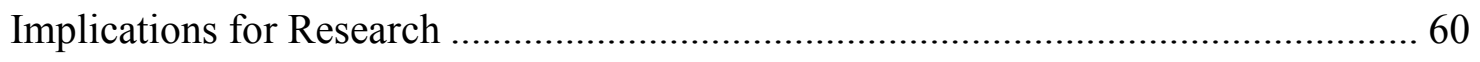

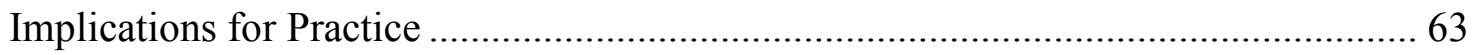

References $\quad 65$

Appendix I. Figures $\quad 78$

Appendix II. Tables $\quad 81$

Appendix III. Measures $\quad 93$ 
Understanding Neighborhood Satisfaction for Individuals with Psychiatric Disabilities:

$$
\text { A Mixed Methods Study }
$$

\section{Introduction}

Housing is internationally recognized as a fundamental human right. As early as 1948, the United Nations Universal Declaration of Human Rights stated that, "Everyone has the right to a standard of living adequate for the health and well-being of himself and of his family, including food, clothing, housing, medical care and necessary social services" (Article 25). Since the passing of this Declaration, a score of other international agreements have adopted a similar stance ${ }^{1}$. It is interesting to note the U.N.'s stipulation that these necessities, rather than simply being present, must be conducive to "health and well-being". This indicates that a standard of quality must be met in order for these rights to be considered upheld. Definitions of health and well-being have continued to evolve as new avenues of research inform our understanding of factors that contribute to or detract from it.

The World Health Organization defines health as “...a state of complete physical, mental and social well-being, and not merely the absence of disease and infirmity" (WHO, 2001, p. 1). Central to this definition is the idea that mental and physical health and social functioning are intertwined and dependent on each other. Healthy functioning in any one of these domains cannot occur without the others. This distinction is

\footnotetext{
${ }^{1}$ For example, the Convention on the Elimination of all Forms of Racial Discrimination (1965); The International Covenant on Economic, Social, and Cultural Rights (1966); the International Covenant on Civil and Political Rights; the Convention on Rights of Persons with Disabilities (2006) http://www.ohchr.org/EN/Issues/Housing/Pages/InternationalStandards.aspx
} 
particularly pertinent given the current prevalence of mental illnesses ${ }^{2}$ and their subsequent impact on important life domains. Current estimates are that one in four people will experience a diagnosable mental illness at some point in their lives (WHO, 2001). In fact, mental illnesses are five of the ten leading causes of disability, and a major source of lost disability-adjusted life years worldwide (Murray \& Lopez, 1996; WHO, 2001; Ustün, 1999). Depression alone is predicted to be the second leading cause of global disease burden by 2020 (WHO, 2004). Mental well-being is recognized as a basic human right, and also a protective factor against mental and physical illnesses (Raphael, Schmolke, \& Wooding, 2005; WHO, 2004). Therefore, interventions seeking to promote the health and well-being of individuals with psychiatric disabilities (PD) must consider this intertwined nature of health, recognizing that individuals with PD may experience challenges not only with psychiatric symptomatology, but also with corresponding physical ailments and detriments in social relationships.

Because people are nested within their communities, cities, and geopolitical contexts, factors existing at each of these levels can impact individual health and wellbeing. Of these domains, community life may be especially important to individual health because of its direct and constant influence on day-to-day experiences (Sarason, 1974; Carling, 1995). Perhaps even more important when individuals face the additional

\footnotetext{
${ }^{2}$ The conversation around labeling with regards to mental illnesses is an important one, and not something that can be covered within the confines of this document. With respect and with this in mind, the term "psychiatric disability" and the abbreviation "PD" will be used throughout the paper when referring to individuals with serious mental illnesses, per Paul Carling's recommendation (1995, p.2). When referring to previous studies, this document uses terminology consistent with the source being cited (e.g., serious mental illness); for the purposes of this study "serious mental illness" can be read as being interchangeable with "psychiatric disability".
} 
challenge of a psychiatric disability, housing environments must take into account the full definition of health and well-being in order to be conducive to healthy functioning. In recognition of this, developing housing sites that promote positive health outcomes has been the focus of a considerable amount of public health policy and community-based research in recent years (Thornicroft, Alem, Santos et al., 2010; Wong and Stanhope, 2009; Wong and Solomon, 2002; Mueser et al, 1998).

The U.N.'s conception of housing that is "adequate" to healthy outcomes is interesting in that it is a flexible term, perhaps left intentionally open to interpretation in the recognition that adequate for some might not be adequate for all. This is the case when individuals with physical or psychiatric disabilities (PD) require accommodations in order to manage the demands of everyday life. While some might find its vagueness frustrating, arguably the power in the term lies in the opportunity to define it scientifically for a given population (in the case of this study, individuals with PD). In order to do so, a discussion of the historical context of housing for individuals with PD is warranted.

Prior to the Kennedy administration in the United States, "adequate" housing for individuals with PD consisted of warehousing individuals in infamously deplorable conditions in state-run psychiatric institutions. The Community Mental Health Act in 1963 heralded the onset of the deinstitutionalization movement, which aimed to end the inhumane treatment in many of the hospitals and restore individuals to life in communities (Carling, 1995). This shifted responsibility for service provision to communities, which understandably needed funding to be able to supply needed services. 
In 1980, President Carter signed the Mental Health Systems Act which mandated federal funding to community support services, a plan which would have provided adequate resources to states had it not been repealed by the Reagan administration the following year. As a result, the closure of psychiatric hospitals forced individuals out into communities that were largely unprepared and unable to afford the influx of people needing diverse services, health care and homes. Many individuals were left homeless, with no way to pay for treatment or housing.

Significant progress has been made in the five decades since deinstitutionalization began, although the gap in needed resources has never been adequately filled. Mental health care values and policy have shifted toward integrating individuals with psychiatric disabilities into the community (Carling, 1995; Mueser et al., 1998) and offering the "least restrictive environment" possible (Thornicroft, Alem, Santos et al., 2010, p 68). In 2006, signatories of the United Nations Convention on the Rights of Persons with Disabilities recognized the equal rights of individuals with disabilities to "have the opportunity to choose their place of residence and where and with whom they live on an equal basis with others and [not be] obliged to live in a particular living arrangement" (United Nations General Assembly, Article 19a). Essentially, this means that, whenever possible, individuals must have self-determination and choice and be active participants in their treatment planning and recovery. In addition, the Convention recognized "The equal right of all persons with disabilities to... their full inclusion and participation in the community" (United Nations General Assembly, 2006, Article 19). This perspective emphasizes the value of community and the importance of living in settings that 
maximize and maintain connections to family, friends, work and natural supports in the community (Thornicroft et al, 2010). Supportive independent housing programs - that is, housing with access to community support services - are widely recognized and utilized as being promotive of community integration (i.e., the ability of individual with psychiatric disabilities to live successfully as participating members of the community) (Wong and Solomon, 2002). "Adequate" housing for individuals with psychiatric disabilities, then, involves consumer choice and equality of opportunities, including access to opportunities for community integration (Carling, 1995).

\section{Social-ecological Perspectives}

The aforementioned changes in practice and policy are due in part to growing appreciation for the role that settings play in impacting the health of whole populations. Accordingly, public health interventions must consider the interdependence between people, their health, and the physical and social environments in which they live and participate (Maller, Townsend, Pryor et al., 2005). For example, access to parks and nature (physical environments) can directly impact individual health and well-being by decreasing stress, and indirectly by providing opportunities for recreation and social exchanges (Maller et al., 2005).

The concept of the interdependence of individuals and settings is not a new one. In 1977, Urie Bronfenbrenner, drawing on the early social ecology theories of Kurt Lewin, proposed an approach to studying human development within the contexts of changing environments (Bronfenbrenner, 1977; e.g., Lewin, 1939). He argued that individuals should not be presumed to be separate from their ecological environments, 
which consist of the relationships between persons and their immediate setting (microsystem), the interrelations between major settings (mesosystem), the social structures that govern their immediate settings (exosystem), and the overarching institutional patterns, culture, and politics influencing all other levels (macrosystem) (Bronfenbrenner, 1977).

A Social-ecological Framework for Neighborhoods. Kloos and Shah (2009) suggest that supportive housing environments for individuals with psychiatric disabilities should be investigated using a similar ecological approach that takes into account the multi-layered contexts in which individuals are situated. Their social-ecological framework of housing states that housing environments are influenced by interpersonal relationships and the physical and social environments in which they are situated. In this framework, the physical environment is comprised of the physical quality of the neighborhood (e.g., the quality of sidewalks and availability of transportation) and the housing itself (e.g., quality of the plumbing, presence of pests, etc). Interpersonal relationships are comprised of relationships with neighbors, landlord, and roommates; and the social environment captures perceptions of neighborhood safety and social climate (i.e., the general character of the social milieu where people live, that is a combination of customs, attitudes, and behaviors) (Kloos \& Shah, 2009).

Metraux and colleagues (2012) note that the majority of previous research on housing for individuals with psychiatric disabilities has focused on the housing itself rather than features of the neighborhood, which they propose are likely more important to certain mental health recovery outcomes (e.g., community integration). This indicates 
the need for further research that examines the impact of neighborhood-level factors on individuals. A study on residential satisfaction for residents of low-income housing found that neighborhood satisfaction and housing satisfaction were, in fact, two distinct concepts (Bruin \& Cook, 1997); and a review of previous studies on housing satisfaction for individuals with serious mental illness found a lack of association between housinglevel factors (e.g., size of the dwelling and physical quality) and resident satisfaction (Newman, 2001). Similarly, Wright and Kloos (2007), found that perceptions of neighborhoods are more important in predicting well-being outcomes than housing-level factors.

Neighborhoods are an increasingly utilized unit of analysis for research, policy, and practice, particularly in fields where health disparities are of interest (Coulton, 2012). One of the earliest formalized conceptualizations of what constitutes a neighborhood was proposed in 1906 and utilized by the U.S. Census Bureau in 1910 as a way to study health services in New York City neighborhoods (Krieger, 2006). These areas, originally termed "sanitary areas" because of their utility in planning public health services, are now known as census tracts and are one of the most commonly used conceptualizations of neighborhoods, particularly when divided into smaller block group and census block units (Krieger, 2006). Census tracts have an optimum population of about 4000 people (ranging from 1200 to 8000 ), usually cover a contiguous area, and are intended to be relatively stable to allow comparisons from census to census (U.S. Census Bureau, 2012). Census tracts were delineated because of the growing understanding of the role that neighborhood context plays in shaping individual and community health. A federally 
released report on population health, Shaping a Vision of Health Statistics for the $21^{\text {st }}$

Century, graphically depicts population health as being encompassed by community attributes (e.g., the built environment, social attributes, and economic resources), which are encircled by the broader cultural, natural and political context (Friedman, Hunter and Parish, 2002). This speaks to the need to understand individuals as being influenced by their neighborhood contexts, and to therefore use an appropriate level of analysis that captures the nuances of community life (e.g., the neighborhood level).

The present study uses an abbreviated version of the Kloos and Shah (2009) framework to investigate how relationships between individuals and their environments influence satisfaction with their neighborhood as a place of residence. Rather than including both housing and neighborhood-level factors as in the original approach, the present study investigates neighborhood satisfaction using only neighborhood-level predictors. This study will fill a gap in the housing literature for individuals with psychiatric disabilities by exploring the impact of neighborhood environments on resident satisfaction.

Employing only the neighborhood-level predictors from the Kloos and Shah (2009) framework, this study will investigate residents' neighborhood satisfaction as predicted by the neighborhood's physical and social environment. Although described as a separate component in the original framework (i.e., interpersonal relationships tied to housing), for the purposes of this study relationships with neighbors are conceptualized as being part of the neighborhood social environment, alongside neighborhood social climate and safety. 


\section{Objective Measures versus Subjective Perceptions}

This study also aims to contribute to the methodological debate concerning the relative importance of subjective ratings of environment (such as residents' perceptions of neighborhood quality) compared to more objective measures (for example, researcherrated neighborhood quality) in predicting individual satisfaction with the housing environment. Several studies have demonstrated that subjective experiences of one's housing environment are more predictive of psychosocial and health outcomes (e.g., mental health recovery, community integration, and psychiatric distress) than third-party ratings of the same environment (Townley \& Kloos, 2014; Wright \& Kloos, 2007; Stiffman et al., 1999; Yanos et al., 2007). For example, in a study of 373 individuals with psychiatric disabilities residing in 66 neighborhoods in the southeastern United States, Townley and Kloos (2014) found that individual perceptions of neighborhood quality were more closely related to psychological well-being than either aggregated perceptions or researcher ratings of the environment. Similarly, Brusilovskiy and Salzer (2012) used Geographic Information Systems (GIS) analyses to determine if US Census data on neighborhood crime, sociodemographic information, and housing stock quality predicted well-being outcomes for a sample of individuals with psychiatric disabilities. They found no relationship between the objective neighborhood quality data and individual outcomes and concluded that individual perceptions of neighborhoods were more important to well-being outcomes than more objective markers. Coulton (2012) argues that individual perception is critical even to the conceptualization of what constitutes a neighborhood; and researchers should therefore employ methods that 
adequately take into account individual perceptions of neighborhood context. The present study will investigate whether these findings hold true when investigating neighborhood satisfaction as an outcome. 


\section{Study Overview}

This study draws on dictums regarding rights to adequate and health-promoting housing environments and argues that resident satisfaction can be used as an indicator of whether the housing environment is meeting these objectives. Resident satisfaction is shaped by neighborhood experiences, which previous studies have demonstrated to be critical to individual health and wellbeing outcomes. Below, I summarize findings from several of these keys studies, as well as their relation to resident satisfaction in general and neighborhood satisfaction specifically. This study combines multiple methods of inquiry, including geospatial, quantitative and qualitative survey data, to provide a unique analysis of the manner in which neighborhood variables operate in relation to neighborhood satisfaction. Subjective and objective measures of the social and physical environment of the neighborhood are hypothesized to contribute differentially to neighborhood satisfaction.

Proposed predictors of neighborhood satisfaction are discussed below. An analytical plan is described that will parse out the effects of subjective and objective variables, as well as social and physical environmental variables. First, analyzing differential effects of subjective and objective variables has implications for research methodology. For example, if subjective predictors explain more of the variance in neighborhood satisfaction, researchers may want to place more emphasis on collecting data on participant perceptions rather than objective measures of neighborhood environment. Second, grouping predictors into social and physical aspects of the neighborhood environment will contribute to knowledge of the complex contexts in 
which individuals are situated. For example, if the social context of the neighborhood explains more variance in neighborhood satisfaction, programs seeking to develop new housing sites should pay careful attention to the social climate, diversity, and safety of the neighborhood. To contextualize quantitative findings, data from open-ended questions about what residents like and dislike about their neighborhood will be analyzed and incorporated into the broader discussion of resident satisfaction. Finally, I discuss the potential implications of this work as well as future directions.

\section{Resident Satisfaction}

A discussion of the right to adequate and health-promotive housing would be incomplete without a consideration of the role of resident satisfaction. Resident satisfaction is comprised of the evaluative perceptions of physical and social environments in which individuals live. This study focuses on residents' satisfaction with their neighborhoods; however, this distinction is not always made in the literature, and frequently housing and neighborhood satisfaction are combined in ratings of resident satisfaction. Below, I provide a summary of the resident satisfaction literature. Where possible, neighborhood satisfaction is distinguished from satisfaction with housing. Individuals with PD frequently live in low-income and distressed neighborhoods. Wong and Stanhope (2009) compared characteristics of residential neighborhoods for individuals with developmental disorders to those of individuals with psychiatric disabilities and found that individuals with PD lived in neighborhoods that were comparatively more distressed, more spatially dispersed, and more unstable. On the other hand, a more recent study by Metraux and colleagues (2012) found that individuals with 
PD actually lived in neighborhoods with relatively more resources (e.g., doctors' offices, shops within walking distance) than those in the general population. Because of the importance of subjective experiences in predicting well-being outcomes (Townley \& Kloos, 2014; Wright \& Kloos, 2007; Stiffman et al 1999; Yanos et al., 2007), it is necessary to understand the extent to which these physical properties influence how satisfied residents feel about their neighborhoods. Resident satisfaction might then be seen as an indicator of the quality of the environment. In addition, resident satisfaction has been shown to have implications for housing stability and residential mobility factors which are of critical significance to individuals with PD.

Resident satisfaction as an indicator of quality. Satisfaction (as measured in a variety of domains, including urbanicity of environment, relationships, and income) has been considered an important indicator of quality of life (Campbell, 1976). The utility of measuring resident satisfaction is due to its predictable relationship with the residential environment (Weideman et al., 1982). That is, aspects of one's housing and surrounding neighborhood consistently impact satisfaction. Therefore, if housing interventions are concerned with whether the housing environment is adequate for the health and wellbeing of its residents, they might reasonably view resident satisfaction as a valid and reliable indicator of the quality of the social and physical characteristics of the neighborhood. For example, increased perceptions of safety and quality are predictably associated with increased resident satisfaction (Bruin \& Cook, 1997). In addition, residential satisfaction is positively associated with the presence of social networks, increased tenant involvement, and improved self-efficacy (Bruin \& Cook, 1997). 
Residential satisfaction and stability. Satisfaction with one's place of residence is an important predictor of residential stability (Tsemberis et al., 2003; Wright and Kloos, 2007). Srebnik and colleagues (1995) found that choice in housing was positively related to resident satisfaction, tenure, and psychological well-being, supporting the intuitive conclusion that when people are happy with their living arrangements, they are more likely to want to continue living there; and further, that this stability and satisfaction contributes to overall well-being. One mechanism explaining the link between satisfaction and residential tenure may be the development of social ties. The longer that individuals live in one place, the more likely they are to build social relationships in the locality, and the stronger their psychological attachment to the community is expected to be (Kang \& Kwak, 2003). Stable housing offers the opportunity to build secure relationships, which are important to psychological well-being (Carling, 1995). Residential stability can also have direct implications for mental health. For individuals with psychiatric disabilities (PD), perceptions of and satisfaction with housing environments have also been shown to play an important role in reducing psychiatric symptom distress (Wright and Kloos, 2007), which may in turn reduce utilization of high-cost mental health services. Similarly, one study found that highly distressed individuals with histories of homelessness and alcohol dependency showed significant improvement in psychiatric symptoms after being in stable housing for one year (Tsemberis, Kent \& Respress, 2012). Residential stability may be particularly important to individuals with $\mathrm{PD}$, who not only experience higher rates of residential mobility but are also particularly susceptible to the associated costs. 
Importantly, residential mobility is associated with lower levels of subjective well-being (Oishi, 2010). In one study, residential mobility was associated with increased rates of major depression, schizophrenia, and substance use (Silver, Mulvey, \& Swanson, 2002). Individuals with PD living in supportive housing often have histories of homelessness and/or housing instability—factors which exact significant psychological, physical, social, and economic tolls. For example, ever experiencing homelessness has been shown to be predictive of higher rates of psychiatric distress, and this distress increases with the number of months spent homeless. Furthermore, months spent homeless has been shown to be predictive of lower perceptions of mental illness recovery (Castellow, Kloos \& Townley, 2015).

Individuals with psychiatric disabilities are also more likely to experience isolation and have limited social connections. Residential mobility can compound these issues by contributing to the fragmentation of existing social supports. Residential mobility also discourages individuals from engaging in procommunity actions (e.g., working to bring about positive change for the sake of their community) (Oishi, 2010; Oishi et al., 2007), and potentially further limits opportunities for community inclusion. By taking into account residents' satisfaction with their neighborhoods, housing programs may be able to reduce residential mobility (and thus its associated costs) and create environments that are conducive to increased residential tenure. I turn next to a discussion of physical and social environmental variables that likely impact individuals' satisfaction with their neighborhoods. 


\section{Neighborhood Physical Environment}

As was discussed previously, individuals with serious mental illnesses are more likely to reside in lower SES and distressed neighborhoods and houses that are of poorer physical quality (Byrne et al., 2013; Metraux et al., 2012; Wong \& Stanhope, 2009). This is problematic given that physical environmental factors such as the quality of the housing site (e.g., aesthetics, plumbing, and pest control) and surrounding neighborhood (e.g., sidewalks, lighting, and presence of green spaces) have been shown to be important predictors of residents' recovery outcomes (Kloos and Shah, 2009). For example, improvements in housing are associated with a decreased need for services (Newman et al., 1994); and the relative availability of neighborhood stores and transportation is associated with higher adaptive functioning (i.e., ability to handle common demands of living independently) (Kloos and Shah, 2009). Baker and Douglas (1990) found that individuals with PD living in housing that was physically inadequate were more likely to have maladaptive behaviors, regardless of the amount of support services they received. Their measure of physical inadequacy included a rating of the neighborhood physical quality as well as housing-level variables, although the percentage of variance accounted for by neighborhood quality alone was not reported. The study also had several design problems as noted in a review by Newman (2001), highlighting the need for further clarity on the influence of neighborhood physical conditions on important outcomes for individuals with PD.

Neighborhood physical deterioration has also been shown to be negatively correlated with neighborhood satisfaction, social contact, and social capital in non- 
clinical samples (Kruger et al., 2007). In a phone survey of 801 residents in Flint and Genesee counties in Michigan, Kruger and colleagues found that the association between structural deterioration of the neighborhood and perceived stress and depressive symptoms was mediated by social behavior and perceptions of the neighborhood social climate (2007). That is, as a result of neighborhood deterioration, residents reported decreased contact with their neighbors and increased safety concerns, which in turn influenced their self-reported mental health. The neighborhood physical quality impacted the social experiences of the residents, indicating that these variables operate simultaneously and should therefore be analyzed together. These important consequences of poor neighborhood physical quality are likely to negatively impact residents' overall neighborhood satisfaction. On the other hand, Harkness and colleagues (2004) found that neighborhoods with no outward appearances of deterioration and with newer houses were associated with reduced mental health care costs, indicating important effects of neighborhood physical quality on individuals with PD. The presence of front porches, traffic calming devices, and the absence of bars on windows, litter, and graffiti were correlated with increased neighborliness, providing additional support for the need to consider neighborhood physical quality as an important predictor of satisfaction (Wilkerson et al., 2011).

Neighborhood Walkability. Neighborhood walkability has been shown to be important to physical and social health outcomes. For example, individuals who live in walkable neighborhoods walk more and have lower body-mass indices; conversely, individuals living in less walkable neighborhoods have more weight-related chronic 
illnesses and lower self-reported ratings of health (Doyle et al., 2006). In addition, individuals who live in walkable neighborhoods have higher levels of social capital and are more likely to know their neighbors, participate politically, and be socially engaged (Leyden, 2003).

Relatively little is known about pedestrian preferences. Weinstein Agrawal and colleagues found that pedestrians who walked to train stations walked an average of a little under half a mile, which was considerably farther than the conventional expectation of a quarter to a third of a mile for access to transportation (2008). When measured in terms of airlines (that is, straight lines; 'as the crow flies'), Mouden and colleagues found that participants perceived a walkable distance in their neighborhood as an area of approximately $1.4 \mathrm{~km}$ by $1.4 \mathrm{~km}$ (about .87 square miles; 2006).

For participants, the most influential factor in planning their routes was the distance or time it would take to walk, followed by the perceived traffic safety along the route. A half-mile is about a 10-minute walk for a fully ambulatory person (Dittmar \& Poticha, 2004). Some studies have used Euclidian distance (mapping a circle or proximity buffer around the housing site) to determine the half-mile area (Metraux et al., 2012), while others take into consideration the fact that individuals walk along roads to reach their destinations (Brusilovsky \& Salzer, 2012). Another tactic is to calculate the walkable area using a census block group that consists of several street blocks (census blocks comprise block groups, which in turn comprise census tracts) (Wong \& Stanhope, 2009). More recently, Walk Score (www.walkscore.com), a publicly available website used to calculate the number of nearby destinations or amenities, has emerged as a 
potential tool to be used in place-based research (Carr, Dunsiger, \& Marcus, 2010).

However, while numerous methods for assessing walkability have been suggested in the

literature, very few studies have examined the likely relationship between walkability and satisfaction with the neighborhood.

\section{Neighborhood Social Environment}

Social environment factors have also been shown to be important to health and well-being outcomes. Because a community consists of a physical locale as well as a social experience (Bromley, 2013; Ware et al., 2007), simply housing individuals with psychiatric disabilities in community settings (e.g., supportive or supported housing) is not alone sufficient to ensure that meaningful community engagement will follow. Individuals living in supportive housing report less social contact with neighbors and lower levels of life satisfaction than other community members (Aubry and Myner, 1996); have smaller, less connected, less diverse social networks; report fewer meaningful relationships; and have social networks consisting more of family members and relationships formed in mental health contexts rather than in the broader community (Eklund and Hansson 2007; Schwartz and Gronemann 2009; Segal, Silverman and Temkin, 1997). This lack of integration and full participation in community life comes at a significant cost because individuals are missing out on important opportunities to build social support and engage in meaningful community roles. These findings speak to the importance of examining the impact of the neighborhood social environment on resident outcomes. 
Kloos and Shah (2009) conceptualize the social environment in the context of supportive housing as the "social experiences related to community living" (p. 321), including perceptions of belonging or discrimination, as well as safety for both self and property. Social aspects of neighborhoods can impact the functioning of people with serious mental illnesses; and poor quality social environments can have negative effects on a variety of outcomes. Conversely, positive social experiences with neighbors and others in the immediate environment have been shown to be predictive of improved wellbeing (Kloos \& Shah, 2009; Kloos \& Townley, 2011) and are, thus, likely to have a strong impact on neighborhood satisfaction.

Safety. Perceptions of neighborhood safety have been shown to be related to physical and mental health outcomes in nonclinical samples (Ziersch et al., 2005). Yanos and colleagues note that safety has been relatively understudied among individuals with mental illness (2004). Cutrona et al. (2005) found that in a non-clinical sample of 720 African American women, neighborhood-level poverty and social disorder (i.e., drug use and delinquency) predicted the onset of major depression after controlling for individuallevel demographics. In another study, individuals with mental illnesses who reported having difficulties fitting into their neighborhood also reported feeling a lack of neighborhood safety (Yanos et al., 2004). Feelings of danger and of being unsafe can interfere with daily functioning and cause individuals to become isolated in their homes (Zeldin and Topizes, 2002). This complements work by Townley and Kloos (2011), who found that perceptions of neighborhood safety explained a small but significant amount of variance in sense of community for individuals with psychiatric disabilities living in 
supported housing. In some cases, concern about neighborhood crime can overwhelm otherwise positive perceptions of the neighborhood (Newman, 1994).

Further, concerns about neighborhood safety can impact physical and mental health. In a non-clinical sample of 2402 women in disadvantaged neighborhoods in three major US cities, chronic environmental stressors such as crime, harassment, and social disorder predicted physiological and psychological stress responses, including anxiety, depression, weakness, nausea, and chest pains (Hill, Ross \& Angel, 2005). Similarly, Kruger and colleagues (2007) reported that fear of crime was associated with lower neighborhood satisfaction and higher perceived stress and depressive symptoms among a non-clinical resident sample (Kruger et al., 2007). Neighborhood safety can have implications for physical health when it interferes with residents' ability or desire to engage in physical activity. A review of previous studies on the relationship between subjective and objective measures of safety and physical activity found inconsistent results across the literature, due in large part to the disparate ways in which safety has been operationalized (Foster \& Giles-Corti, 2008). Objective measures of safety have been obtained by analyzing diverse sources of data, including the number of registered cases of violence per 1000 inhabitants (Piro et al., 2006); county rates of police-reported serious crimes (e.g., murder, forcible rape, robbery, and aggravated assault) (Doyle, Kelly-Schwartc, Schlossberg, \& Stockard, 2006); and by ratings from municipal services employees of the amount of police attention in an area (van Lenthe, Brug, \& Mackenbach, 2005). Safety, as measured by crime rates, has been associated with decreased walking and increased BMI (Doyle et al., 2005). In one study, higher 
neighborhood violence was associated with decreased physical activity for men, and lower subjective perceptions of safety were associated with decreased physical activity for women (Piro et al., 2006). Clearly, perceptions of safety are important to residents and are likely to influence overall satisfaction with the neighborhood.

Social Climate. Neighborhood social climate is a relatively new construct in supportive housing literature that captures perceptions of tolerance for diversity and community acceptance (Wright \& Kloos, 2009). Community acceptance and tolerance may be particularly important for individuals with psychiatric disabilities, who on average have fewer opportunities for community engagement (White, Simpson, Gonda, Ravesloot \& Coble, 2010). Further, when these opportunities are present, individuals often face the added barrier of stigma, or negative attitudes about mental illnesses (Link et al., 2014; Pescosolido, Martin, Long, Medina, Phelan \& Link, 2010). Experiences of stigma and social rejection can permeate the lives of individuals with psychiatric disabilities (PD), due to harmful portrayals and appraisals of mental illness in the media, popular lore, peer relations, and personal interactions (Link et al., 2014). For example, studies continue to demonstrate that people are unwilling to work with or befriend someone with schizophrenia (Pescosolido et al., 2010). In addition, stigma may actually exacerbate symptom distress by contributing to self-imposed isolation (Kessler et al., 2001). It also strongly predicts poorer quality of life and low self-esteem (Rüsch et al, 2014; Link et al., 2014).

According to findings from Wright and Kloos (2007), neighborhood social climate may be the "single most predictive housing environment factor" (p. 8) in 
explaining variation in well-being for individuals with serious mental illness. The perception of a more welcoming and tolerant neighborhood is associated with less psychiatric distress (Kloos and Shah, 2009). Consistent with this finding, another study found that neighborhood social climate fully mediated the relationship between neighborhood experiences and psychiatric distress (Kloos and Townley, 2011). A positive social climate may be particularly important for housing stability, as research participants were less likely to move at 12 months if they gave favorable reports of their neighborhood and neighbors at a baseline interview (Kloos and Shah, 2009). Given the significance of perceiving a welcoming and tolerant environment for individuals with mental illness, it is likely that a positive neighborhood social climate will be predictive of resident satisfaction.

Neighboring. Interpersonal relationships among neighbors are similarly predictive of important recovery outcomes. Previous studies have shown that everyday encounters with other community members in public places increase participants' sense of connection to the community, and that these naturally existing supports are important to individual recovery and community living (Townley, Miller \& Kloos, 2013). Positive relationships with neighbors have been shown to be strongly correlated with increased perceptions of social support (McDaniel, 2008). This is significant, given that social capital (i.e., trust, involvement in formal and informal networks, and having friends to rely on) accounts for a significant amount of variance in emotional health (Rose et al., 2000); and perceptions of social support are inversely related to psychiatric distress and positively correlated with recovery (McGregor, 2008). Qualitative data from residents of 
a psychiatric hospital indicated that they viewed relationships as connections to the wider community, and a source of hope (Beal et al., 2005). Despite the apparent importance of relationships with neighbors, there has been very little attention in mental health research to the influence of relationships with neighbors on resident satisfaction.

\section{Study Purpose and Research Questions}

The proposed study will utilize mixed methodology (qualitative and quantitative) to gain a more in-depth understanding of neighborhood influences on resident satisfaction. The benefit of integrating these approaches is that the strength of each method can be used to complement the other (Crooks et al., 2010). This approach is particularly relevant when studying contextual factors that contribute to neighborhood experiences because it allows for the integration of indices that cover multiple domains (e.g., geospatial data, surveys, and narrative reports) (Townley, 2012).

This study draws on the social ecological approach to studying housing environments suggested by Kloos and Shah (2009). In accordance with this approach, this study will explore the extent to which neighborhood satisfaction is predicted by perceptions of neighborhood social and physical environments. The aim of this study is to assess residents' satisfaction with their neighborhoods; and therefore, only neighborhoodlevel predictors will be included in the analyses. In addition, this study will explore the relative influence of subjective and objective factors in predicting neighborhood satisfaction. The following three research questions and corresponding hypotheses are proposed to examine the relationships between key variables outlined above. 
Research Question 1: What are the relative influences of neighborhood social and physical environments on neighborhood satisfaction? (see Figure 1 below, and in Appendix I)

As discussed above, the social climate of the neighborhood has the ability to shape experiences of community life and is expected to directly impact residents' neighborhood satisfaction. This study proposes that individuals who feel that their neighborhood is relatively safe and welcoming and who have good relationships with their neighbors will be more satisfied with their neighborhoods.

Neighborhood physical quality can also be important to community life. Access to transportation, the quality of neighboring buildings and sidewalks, and availability of goods and services are vital components of daily living that enable individuals to meet their basic needs. When these resources are unavailable or in disrepair - or conversely, readily accessible and of high quality - residents will be directly impacted. Therefore, neighborhood satisfaction is likely to vary with the perception of the physical quality of the neighborhood. This study proposes that:

H1a: The neighborhood social environment and physical environment will explain a significant portion of the variance in neighborhood satisfaction.

Furthermore, because of the pervasive influence of the social environment on community living, and in line with findings in previous studies (e.g., Bruin \& Cook, 1997), perceptions of the social environment are likely to be the strongest and most salient predictors of neighborhood satisfaction, over and above the influence of the physical environment: 
H1b: The social environment aspects of the neighborhood will account for more variance in neighborhood satisfaction than the physical environment of the neighborhood.

Figure 1. Neighborhood satisfaction predicted by neighborhood social and physical environment factors.

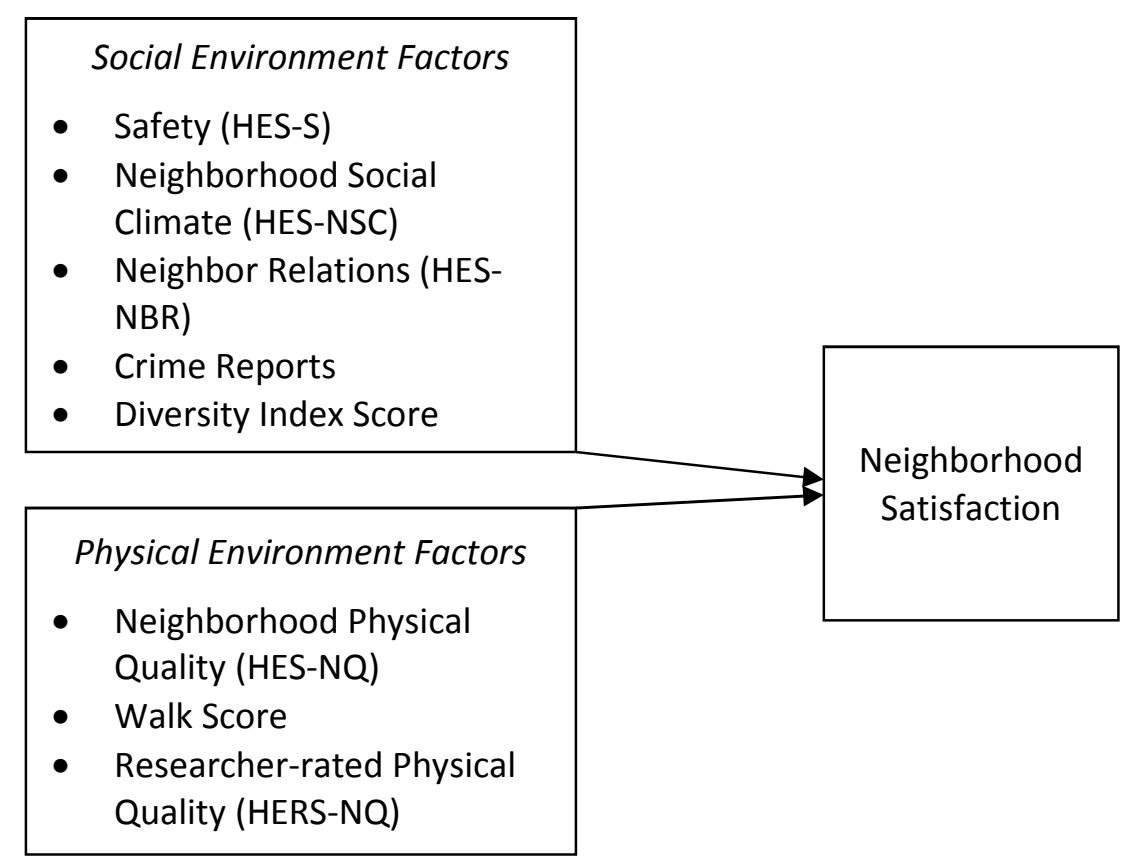

Research Question 2: What are the relative influences of subjective and objective indicators of neighborhood environments on neighborhood satisfaction? (see Figure 2 below and in Appendix I)

Previous studies have shown that subjective perceptions of the environment are more predictive of resident outcomes than researcher-rated or objective measures of the environment (Townley and Kloos, 2014; Wright and Kloos, 2007). Therefore, we expect that the subjective measures of the environment will explain more of the variance in neighorhood satisfaction than objective measures: 
H2: Subjective perceptions of environment will account for more variance in neighborhood satisfaction than objective measures of environment.

Figure 2. Neighborhood satisfaction predicted by subjective and objective neighborhood factors.

Subjective Factors

- Safety (HES-S)

- Neighborhood Social Climate (HES-NSC)

- Neighbor Relations (HESNBR)

- Neighborhood Physical Quality (HES-NQ)

\section{Objective Factors}

- Crime Reports

Neighborhood

Satisfaction

- Diversity Index Score

- Walk Score

- Researcher-rated Physical Quality (HERS-NQ)

Research Question 3: What factors do residents report as being important or detrimental to their neighborhood satisfaction?

Qualitative data from residents on factors that they like or dislike about their neighborhood may be important in identifying additional aspects of community life that influence neighborhood satisfaction. Qualitative data have the potential to capture concepts and nuances that are missed by quantitative survey scales because respondents are not constrained to predetermined response options. Data from open-ended questions about what residents like or dislike about their neighborhoods has the potential to corroborate quantitative results from the previous research questions, or illuminate 
avenues for future research. Morgan (1998) recommends making a priority decision regarding whether qualitative or quantitative data will be prioritized in a mixed methods study. This study prioritizes quantitative data, and qualitative data is used as a complementary source of information in order to contextualize those findings. Broadly, it is expected that participants' reports of factors they like and dislike in their neighborhoods will include a variety of experiences that reflect physical and social components of the environment similar to those included in the quantitative analyses described above, while also illuminating important factors to include in future research. 


\section{Methods}

\section{Participants}

This study utilizes data collected from 172 individuals with mental illness residing in a supportive housing program in Portland, Oregon. Housing sites were located in 16 neighborhoods in the greater Portland metropolitan area (see Figure 3 in Appendix I for a map of the housing sites). Residents of Cascadia Behavioral Healthcare's supportive housing sites hold their own leases and are subject to the same local and federal laws as all rental housing in Portland, Oregon. The housing sites have Resident Service Coordinators who are employed by Cascadia and generally spend 12 to 15 hours a week on-site to help connect residents to community and mental health care services. Residents are not required to be actively utilizing mental health or substance use treatment to live in Cascadia supportive housing, but they must have a diagnosed mental health disability.

Residents are allowed to request to transfer to a different unit within the same housing site, but transfers to other housing sites require that the individual be placed on a waiting list, which is generally quite lengthy. Resident turnover is very low. Jim Hlava, Vice President of Cascadia Housing, estimates that occupancy remains at 97 to $98 \%$ in a given year (J. Hlava, personal communication, April 19, 2016). All 323 eligible Cascadia supportive housing residents were invited to participate via a letter that advertised a research project on resident perspectives on housing, and asked to contact the principal investigator if they were interested. Thus, $54 \%$ of all eligible residents participated in this study. 
Demographics. Participants ranged in age from 22 to $72(M=50.04, S D=9.66)$. $56 \%$ identified as male and $43 \%$ identified as female, and 2 respondents identified as non-binary gender (1\%). The most common primary diagnosis was Bipolar 1 or $2(28 \%)$, followed by schizophrenia-spectrum (25\%), major depression (19\%), and Anxiety (18\%). The majority of participants were white (68\%), and $24 \%$ were black. The remaining participants identified as Latino (2\%), Native American (2\%), Asian (1\%), or other/not listed (3\%). Participants had resided in their current housing for an average of 5.6 years. In the last 6 months, $81 \%$ had taken psychiatric medication and $70 \%$ had participated in individual therapy. $20 \%$ reported being hospitalized for a mental health reason since moving into housing. $76 \%$ reported a history of homelessness. The average age of first becoming homeless was 32 , and participants reported a mean of 3 lifetime episodes of homelessness. 93\% were receiving Medicaid and 94\% received food stamps. 84\% were receiving a housing subsidy at the time data were collected.

\section{Measures}

Neighborhood satisfaction. Residents' satisfaction with their housing was measured using the Housing Environment Scale - Resident Satisfaction (HES-RS; Wright and Kloos, 2007). For this study, two of the five questions from the original scale were relevant to neighborhood-level experiences. For the question, "How does your current neighborhood compare to your previous neighborhood?" responses were captured with a three point Likert scale, and recorded as (1) Better, (2) Same, or (3) Worse. Participants were also asked "How satisfied are you with this neighborhood as a place to live?" and responded on a 5 point Likert scale from (1) Very dissatisfied to (5) Very 
satisfied. Consequently, the neighborhood satisfaction variable is comprised of two questions with different response scales ( 1 to 3 and 1 to 5 point Likert scales). To obtain the scale score and aggregate these different response options, raw rescaling of items was used whereby the neighborhood comparison question was scored 1,2, and 3; and the neighborhood satisfaction questions was scored 1, 1.5, 2, 2,5, and 3 in the manner recommended by Townley and Kloos (2011). The internal reliability (i.e., Cronbach's alpha) for the scale was .61 , which has been argued to be adequate in exploratory studies in the social sciences, particularly when utilizing scales with a small number of items (Aron \& Aron, 1999; Hair, Black, Babin, Anderson, \& Tatham, 2006).

\section{Social environment.}

Neighbor relations. Relationships with neighbors were measured using the Housing Environment - Neighbor (HES-N) measure developed by Kloos and Shah (2009). Participants indicated their level of agreement to each of 9 statements, from (1) Strongly disagree to (5) Strongly agree. Example statements include "I can count on a neighbor for help when I need it" and "My neighbors keep an eye on my apartment when I am gone”. The internal reliability for this sample was .83 .

Subjective measures of safety. Safety was measured using the Housing Environment Scale - Safety (Kloos and Shah, 2009). The 9 item scale assesses perceptions of neighborhood safety, and includes items such as "How often have people had things stolen from their apartment (place, home)?" Participants indicate the frequency of crime and safety related events on a scale from (0) Never to (6) Once a day. The internal reliability for this sample was .86 . 
Objective measures of safety. As discussed above, neighborhood crime data are often used as a proxy for objective safety. This study uses data on annual rates of property and violent crimes per 1000 residents based on statistics from the FBI and U.S. Department of Justice available from NeighborhoodScout.com. These data are available at the census tract level, which is smaller than a zip code but larger than a block group or census block. Census tracts were originally delineated in 1906 as a way to study change over time in New York City neighborhoods (Krieger, 2006), and are therefore an appropriate measure for this study of neighborhood-level factors.

Neighborhood social climate. Perceptions of neighborhood social climate were assessed using the Housing Environment Scale - Neighborhood Social Climate (HESNSC) developed by Kloos et. al (2005). Participants rated 12 statements such as, "Sometimes I feel unwelcome in my neighborhood because of my ethnicity and my cultural background" on a scale from (1) Strongly disagree to (5) Strongly agree. The internal reliability for this sample was .81 .

Diversity Index. Objective measures of diversity will be captured using the Diversity Index for each housing site. The Diversity Index is based U.S. Census data (updated for 2014) on race and ethnicity. The index is available from the block group level, and ranges from 0 (no diversity) to 100 (complete diversity). The index is translated as the percent likelihood that two people chosen at random from the area would be of different racial or ethnic groups. Race is captured as White, Black, American Indian, Asian, Pacific Islander, or Some Other Race. Each race group is further divided into Hispanic or non-Hispanic (Reese-Cassal, 2014). 


\section{Physical environment.}

Neighborhood walk score. Walk scores for each housing site were collected from WalkScore.com, which uses an algorithm to determine walkability based on distance to amenities and pedestrian-friendliness. Walkability scores are calculated by awarding more points to amenities within .25 miles and fewer points to more distant amenities. Points are awarded to 13 categories of amenities, including grocery stores, coffee shops, restaurants, bars, movie theaters, schools, parks, libraries, bookstores, fitness centers, drugstores, hardware stores, and clothing/music stores (Carr et al., 2010). Pedestrianfriendliness is calculated from population density data and road metrics such as block length and intersection density (walkscore.com). Scores range from 0 to 100, with scores in the 0-24 range indicating "car-dependent" neighborhoods (almost all errands require a car), and scores in the 90-100 range indicating a "walker's paradise" (daily errands do not require a car).

Objective neighborhood physical quality. An objective rating of the physical quality of each neighborhood was obtained using the 18-item Housing Environment Rating Scale for Neighborhood Quality (HERS-NQ) (Wright and Kloos, 2007). The scale consists of a dichotomous "present" or "absent" checklist with which the researcher can assess the physical quality of the block area surrounding the housing site, including tended yards, access to bus stops, impassable sidewalks, uncollected trash, and evidence of drug use. HERS-NQ checklists were completed by two trained raters at each housing site. 
Subjective neighborhood quality. Residents' perceptions of the physical quality of the neighborhood were measured using the 14-item Housing Environment Scale Neighborhood Quality (HES-NQ) (Kloos and Shah, 2009). Participants rated statements such as "I have good sidewalks in my neighborhood" from (1) Strongly disagree to (5) Strongly agree. The internal consistency for this sample was .72.

Qualitative reports of neighborhood satisfaction. Additionally, two openended questions were assessed to provide additional context for the quantitative findings of this study. Residents were asked to list three things they liked about their neighborhood and three things they did not like about their neighborhood. Responses will be analyzed using thematic content analysis to uncover salient motifs.

\section{Design and Procedures}

This study utilizes a cross-sectional design and survey methodology. Approval for this study was granted by the Portland State University Internal Review Board in June 2013. The survey protocol included measures of recovery, sense of community, perceptions of neighborhood safety, and additional information on demographics, service use, residential history, and physical and mental health. Data were collected in a one-onone interview format, and participants responded verbally to survey measures administered by a research assistant who recorded responses electronically. Participants read and signed an informed consent document, acknowledging the risks involved (minimal discomfort from questions about sensitive issues) and agreeing to participate in exchange for a $\$ 20$ cash incentive. Interviews took around 1.5 to 2 hours to complete, and were conducted in the participants' homes or housing site common rooms. Steps were 
taken to ensure privacy and comfort, including only proceeding with the interview when common rooms were empty of others and participants felt ready to begin. 


\section{Data Analysis and Results}

\section{Preliminary Analyses}

Prior to conducting analyses, data were screened for outliers or errors in data entry. Because these data are drawn from individuals in different housing sites, it was necessary to first determine if individual perceptions differed systematically by housing site. To determine this, the intraclass correlation coefficient (ICC) was calculated for residents' neighborhood satisfaction by site. In general, ICCs of or above .10 indicate that a significant amount of variance is accounted for by the nesting variable (in this case, the housing site), thus violating the assumption of independence of observations. The computed ICC for neighborhood satisfaction for all the housing sites was .22, indicating that a significant portion of the variance in satisfaction is attributable to the housing site (i.e., that site-level characteristics are influencing differences in the data). This finding would justify a multi-level approach to the analysis. However, on closer inspection of the data, it was apparent that two housing sites in particular appeared to be outliers, with an average neighborhood satisfaction of $1.88(\mathrm{SD}=.62)$ across the two sites compared to an average satisfaction of $2.54(\mathrm{SD}=.46)$ across the remaining fourteen sites; $\mathrm{F}=4.22, p<$ $.01)$. These two sites were accentuating the apparent differences between sites, likely due to their overall lower perceptions of safety $(\mathrm{M}=3.07, \mathrm{SD}=1.85)$ compared to the other fourteen sites $(\mathrm{M}=4.61, \mathrm{SD}=1.19), \mathrm{F}=6.37, p<.01)$. When these sites were removed from the analysis and the ICC was computed for the remaining 14 sites, it fell to .06 .

With the outliers removed, a non-significant portion of the data was accounted for by site and therefore a multi-level modeling approach was unnecessary (i.e., differences between 
housing sites are not significant and do not need to be separately accounted for in the analysis). Thus, research questions 1 and 2 were explored using hierarchical multiple regression.

Listwise deletion was used to address cases where participants were missing more than $25 \%$ of the data (i.e., a completion rate of $75 \%$ or higher) on any variable.

Accordingly, 6 participants who were missing more than two out of nine responses on the perceptions of safety scale (HES-S) were excluded from analyses, resulting in a final sample of 143 participants. No appreciable amount of data was missing for any of the other scales included in these analyses (HES-NQ, HES-NSC, HES-N, or neighborhood satisfaction). The resulting sample was $58.7 \%$ male and $41.3 \%$ female, and ranged in age from 22 to 72, with a mean age of 50.2 years. Race was recoded as white and non-white; accordingly, $31.5 \%$ were non-white and $68.5 \%$ were white. Mental illness diagnoses were recoded as schizophrenia-spectrum and non-schizophrenia spectrum (i.e., all other) disorders. In the final sample, $28 \%$ were diagnosed with schizophrenia-spectrum disorders, and $72 \%$ had non-schizophrenia spectrum disorders.

A power analysis revealed that the minimum sample size required to detect a small effect size $f^{2}$ of 0.11 , with 8 predictors, and a desired statistical power level of .8 , would be 144 participants $(a l p h a=.05)$ (Soper, 2016). With the new sample size of 143 after addressing missing data, the effect size we could expect to detect with the aforementioned parameters would be between 0.11 and 0.12 .

Frequency distributions and summary statistics were examined to ensure data conformed to a plausible range of values for each variable and that the data were 
normally distributed (see Table 1). Tests of skew and kurtosis indicated that three of the study variables (neighborhood satisfaction, subjective safety, and diversity index) were moderately negatively skewed, and crime reports had a strong positive skew. A series of transformations were attempted, but they did not significantly correct skew. Further, all skew and kurtosis values were within an acceptable range according to less conservative guidelines which consider absolute kurtosis values less than 10 and absolute skewness values lower than 3 to be acceptable (Kline, 2011). Therefore, to ease interpretation of the results, the untransformed data were used for analyses. The regression analyses presented below rely on the assumptions of the general linear model, which remains appropriate because the skew was not due to outliers.

A correlation matrix of study variables is presented in Table 2. Neighborhood satisfaction was significantly positively correlated with subjective physical quality, objective physical quality, neighborhood social climate, neighbor relations, subjective safety, and crime reports. It was significantly negatively correlated with neighborhood Diversity Index.

Consistent with similar studies of this population (Rüsch et al, 2014; Katsakou and Priebe, 2006), the present study considered diagnosis, age, and gender as possible covariates. In addition, race has been shown to impact perceptions of neighborhoods (i.e., physical and social disorder; Sampson and Raudenbush, 2004), and was therefore also considered for inclusion as a covariate. Due to the number of variables relative to the sample size, and resultant concerns about statistical power, each of these four demographic variables was first tested to determine if they were correlated with the 
outcome. The results of an independent-samples t-test showed that gender was significantly correlated with neighborhood satisfaction, such that neighborhood satisfaction was significantly lower for females $(N=59, M=2.424, S D=.467)$ than for males $(N=84, M=2.643, S D=.422), t(141)=-.210, p=.05$ (see Table 3). Independentsamples t-tests revealed no significant differences in neighborhood satisfaction by race or diagnosis; similarly, a Pearson bivariate correlation showed that age was not significantly related to the outcome. Therefore, only gender is used as a covariate in the hierarchical linear regressions presented below.

\section{Quantitative Results}

Research Question 1: What are the relative influences of neighborhood social and physical environments on neighborhood satisfaction?

H1a: The neighborhood social environment and physical environment will explain a significant portion of the variance in neighborhood satisfaction.

H1b: The social environment aspects of the neighborhood will account for more variance in neighborhood satisfaction than the physical environment of the neighborhood.

Hypothesis 1a was tested by running two linear regressions. Model 1 regresses neighborhood satisfaction on social environment variables, while Model 2 regresses neighborhood satisfaction on physical environment variables:

Model 1: $\gamma(\text { Neighborhood Satisfaction })_{i}=\beta_{0}+\beta_{1}(\text { subjective safety })_{i}+\beta_{2}($ crime reports $)_{i}+\beta_{3}$ (social climate $)_{i}+\beta_{4}(\text { neighbor relations })_{i}+\beta_{5}$ (Diversity Index $)_{i}+$ Error 
UNDERSTANDING NEIGHBORHOOD SATISFACTION

Model 2: $\Upsilon(\text { Neighborhood Satisfaction })_{i}=\beta_{0}+\beta_{I}(\text { subjective physical quality })_{i}+$ $\beta_{2}(\text { objective physical quality })_{i}+\beta_{3}(\text { WalkScore })_{i}+$ Error

Results indicate that the social environment variables (Model 1) accounted for $24 \%$ the total variance in neighborhood satisfaction, $F(5,137)=8.664, p<.001$. Perceptions of safety, neighborhood social climate, and the neighborhood Diversity Index were significant predictors of residents' neighborhood satisfaction at $p<.05$ (see Table $4)$.

Similarly, the Model 2 regression of physical environment characteristics predicting neighborhood satisfaction was significant, $F(3,139)=5.568, p<.001$, with an $R^{2}$ of .19. Subjective neighborhood physical quality was the only significant predictor, at $p<.001$ (see Table 5).

Hypothesis $1 \mathrm{~b}$ was tested by adding in blocks of predictors and comparing the resulting change in $R$-squared, as well as the beta-weights for individual variables. Social environment variables, which included subjective and crime reports, social climate, neighbor relations, and the Diversity Index for the neighborhood, were entered in as the first block of variables. Subjective and objective neighborhood physical quality, and the neighborhood WalkScore comprised the physical environment, and were entered in as the second block of predictors. Lastly, gender was entered in a third block:

Block 1: Subjective safety, crime reports, neighbor relations, Diversity Index score, social climate

Block 2: Subjective physical quality, objective physical quality, WalkScore

Block 3: Gender 
Resulting in the final model:

Model 3: $r(\text { Neighborhood Satisfaction })_{i}=\beta_{0}+\beta_{1}(\text { subjective safety })_{i}+\beta_{2}($ crime reports $)_{i}+\beta_{3}(\text { social climate })_{i}+\beta_{4}(\text { neighbor relations })_{i}+\beta_{5}($ Diversity Index $)_{i}+\beta_{6}(\text { (subjective physical quality })_{i}+\beta_{7}(\text { objective physical quality })_{i}$ $+\beta_{8}(\text { WalkScore })_{i}+\beta 9(\text { Gender })_{i}+$ Error

The full hierarchical regression model (model 3) was significant, and explained $29 \%$ of the variance in neighborhood satisfaction, $F(9,133)=8.51, p<.001$ (see Table 6). In block one (social environment only), subjective safety and social climate were significantly positively associated with neighborhood satisfaction, while Diversity Index was significantly negatively associated with neighborhood satisfaction $(p<.05)$. The inclusion of physical environment variables in block two did not account for a significant amount of additional variance, supporting Hypothesis $1 \mathrm{~b}\left(\Delta R^{2}=.03, p=.20\right)$. Of the social environment variables, only Diversity Index remained significant $(p=.04)$; of the physical environment variables, only subjective neighborhood physical quality was significant $(p=.04)$. When gender was included as a covariate in block three, the change was significant $\left(\Delta R^{2}=.03, p=.03\right)$. In the final model, only subjective neighborhood physical quality remained significant $(p=.03)$; gender was significant, such that women had significantly lower neighborhood satisfaction $(\beta=-.17, p=.03)$.

Research Question 2: What are the relative influences of subjective and objective indicators of neighborhood environments on neighborhood satisfaction? H2: Subjective perceptions of environment will account for more variance in neighborhood satisfaction than objective measures of the environment. 
Hypothesis 2 was tested by adding in blocks of predictors and comparing the resulting change in $R$-squared, as well as the beta weights for individual variables. The first block of predictors included subjective variables, including individual perceptions of safety, social climate, relationships with neighbors, and neighborhood physical quality. Next, the block of objective variables was added in, which included objective measures of neighborhood safety, objective physical quality, neighborhood Walk Scores, and Diversity Index scores. Gender was entered as a covariate in a third block.

Block 1: Subjective safety, neighbor relations, social climate, subjective physical quality

Block 2: Objective physical quality, neighborhood WalkScore, crime reports, Diversity Index score

Block 3: Gender

Resulting in the final model:

Model 4: $\gamma(\text { Neighborhood Satisfaction })_{i}=\beta_{0}+\beta_{I}(\text { subjective safety })_{i}+\beta_{2}($ crime reports $)_{i}+\beta_{3}(\text { social climate })_{i}+\beta_{4}(\text { neighbor relations })_{i}+\beta_{5}($ Diversity Index $)_{i}+\beta_{6}(\text { subjective physical quality })_{i}+\beta_{7}$ (objective physical quality $)_{i}$ $+\beta_{8}(\text { WalkScore })_{i}+\beta_{9}(\text { Gender })_{i}+$ Error

Model 4 was significant, accounting for $29 \%$ of the variance in neighborhood satisfaction, $F(9,133)=8.5, p<.001$ (see Table 7). In block one (subjective environment variables only), subjective safety and subjective physical quality were significantly positively associated with neighborhood satisfaction $(p<.05)$. The inclusion of objective environment variables in block two did not account for a 
significant amount of additional variance, supporting Hypothesis $2\left(\Delta R^{2}=.04, p=.12\right)$. Of the objective environment variables, only Diversity Index remained significant ( $p=$ $.04)$; and of the subjective environment variables, only subjective neighborhood physical quality was significant $(p=.04)$. As with Research Question 1 , when gender was included as a covariate in block three, the change was significant $\left(\Delta R^{2}=.03, p=.03\right)$. In the final model, only subjective physical quality remained significant $(p=.03)$. Gender was also significant, such that women had significantly lower neighborhood satisfaction $(\beta=-.17, p=.03)$.

\section{Qualitative Results}

Research Question 3: Qualitative reports of neighborhood components that residents like and dislike.

Residents were asked to report up to three things they liked about their neighborhood of residence and three things they disliked. Responses to each of these questions were analyzed using thematic content analysis. Theoretical thematic analysis, rather than inductive thematic analysis, was employed, as we are seeking to answer specific questions that are guided by social-ecological theory (Braun \& Clarke, 2006). The data were analyzed from a constructionist perspective, in which the underlying meaning is expected to be influenced by sociocultural contexts and structural conditions, such as those present in housing sites for individuals with serious mental illnesses.

Data were analyzed using the six phases outlined in Braun \& Clarke's (2006) guide to thematic analysis for psychology. During Phase 1 (familiarization with the data), the principal investigator independently read through the data several times to develop an 
understanding of the material and a list of coding categories. In Phase 2 (generating initial codes), the principal investigator coded each data point using the categories identified in Phase 1. In Phase 3 (searching for themes), the codes were sorted into themes and subthemes (see Table 8 and Table 9).

During Phase 4 (reviewing themes), themes were refined by collapsing categories when there was not sufficient evidence in the data to support the theme; and themes were divided into separate themes when it appeared the theme was too broad. For example, in the "dislike" responses, the theme of crime was subdivided into gang, violent, drug or alcohol, property, safety concerns, and unspecified or other crime. Prostitution was initially included as its own subcategory of crime but was collapsed into unspecified or other because of its low frequency of occurrence. Similarly, lack of entertainment was initially a category used to capture responses such as "boring" or "nothing to do here". Due to the overall low frequency of this category (five participant statements overall), it was collapsed into lack of access to stores/services during Phase 4 based on the assumption that the complaint was in reference to a lack of options for entertainment near the housing site. In the "like" responses, location/access to stores and services, proximity to family, and proximity to park were initially independent categories. During this phase, it was determined that proximity to family was a relatively low-frequency item (five responses) and could be considered part of a broader location category. Proximity to park was similarly considered to be a component of location. Therefore, a broad category was named location, of which access to stores and services, proximity to family, and proximity to park became subcategories. 
In Phase 5 (defining and naming themes), the themes were named to identify the essence of the data they contain. During this phase, descriptions for each theme and subtheme were defined to delineate what was and was not included in each theme (see Tables 8 and 9 for theme descriptions and examples). This phase happened in conjunction with phase 4 , as refining the themes helped to clarify the definition and name of each theme.

In Phase 6 (producing the report), the data were tallied, simple percentages were calculated, key themes were identified, and themes were labeled as either physical or social environment characteristics. Below, I discuss the data management and findings as they relate to the research questions.

Data management, reliability, and validity. Data were tallied using several spreadsheets to organize responses by categories. The spreadsheets contained coded checks to ensure accurate counts of data. For example, the number of participants was known a priori, and respondents had the option to list up to three things they disliked about their neighborhood. If a participant gave two out of a possible three responses, the third blank response was coded as [two], indicating they responded to only two items. The number of [no response/nothing], [one], [two], and [three] codes were summed across to determine if the number of respondents matched the known, or expected, number of participants for each housing site:

$(\#$ participants $)=(\#$ of $[$ no response $/$ nothing] codes $)+(\#$ of [one] codes $)+(\#$ of [two $]$ codes $)+(\#$ of [three] codes $)$ 
Next, the total number of responses was summed by tallying the number of responses in each of the categories identified in tables 8 and 9. These amounts were checked using a simple equation in which the number of [one], [two], or [three] codes was multiplied by their corresponding multiplier (i.e., [one] multiplied by one, etc) and added together along with the number of [no response/nothing] codes. The number of codes is a the same as the number of participants, and the multiplier is the number of responses for each participant. This total was matched to the tally of coded responses for each site.

$$
\begin{aligned}
& (\# \text { of total responses })=(\# \text { of }[\text { no response } / \text { nothing }] \text { codes })+(\# \text { of }[\text { one }] \text { codes }) * 1 \\
& +(\# \text { of }[\text { two }] \text { codes }) * 2+(\# \text { of }[\text { three }] \text { codes }) * 3 \\
& \text { While cumbersome to explain, these equations were simple to input into a }
\end{aligned}
$$
spreadsheet and resulted in the ability to detect at least three counting errors that would have affected the outcome of the qualitative portion of this study. This quality control procedure also meant that raw data and codes were each reviewed numerous times for inconsistencies and errors, thereby improving reliability. Although codes were aggregated at the sample level, responses were coded at site-level, allowing the researcher to conduct a negative case analysis when particular codes were not used at a given site. Reliability is further ensured by the fact that questions were asked with the same wording each time, at the same point during the interview process, minimizing bias due to interviewer phrasing and standardizing survey order effects across participants.

To ensure internal validity, the researcher used a low level of inference for each response rather than assuming meaning in the absence of adequate information. When 
meaning could not be discerned from a response, the response was coded as other. In most cases, due to the focused nature of the questions and the limited amount of text for each response, there were very few responses that were sorted into other because of uncertainty about their meaning. In rare cases when a response seemed to fit into more than one category, the researcher consulted with a subject-area expert to determine the logical grouping. Validity is further evidenced by the complementary results from the quantitative portion of this study whereby, for example, the two outlier sites had significantly lower perceptions of safety on the subjective safety measure and also reported disliking crime in the qualitative component (see results below).

Qualitative findings. Summaries of the responses to the questions What are three things you like about your neighborhood? and What are three things you dislike about your neighborhood? are presented in tables $10,10.1,11$, and 11.1. With regards to things that participants disliked, crime, homelessness, and noise pollution were conceptualized as comprising the social environment, and litter, transportation difficulties, traffic, lack of access to stores or services, physical quality, and location were considered part of the physical environment. By far the most commonly reported disliked neighborhood factor was crime. The two housing sites that were excluded from the quantitative analysis because they had significantly lower scores of neighborhood satisfaction accounted for $46.9 \%$ of all the crime-related responses. This is notable, given that the two outlier sites accounted for only $13.4 \%$ of all respondents, and $16.6 \%$ of all the "dislike" responses.

The most commonly specified type of crime was drug use (39.5\% of crimerelated responses across all sites). Half of all the complaints about drug use were 
accounted for by the two outlier sites (see table 10.1). For the two outlier sites, gangs were also more of a concern than for the other sites, accounting for $80 \%$ of the reports of gang activity, and the next highest category of specific types of crime. Another factor supporting the low neighborhood satisfaction of the outlier sites was that zero respondents indicated they had no complaints, whereas $11.4 \%$ of participants from the other 14 housing sites indicated there was nothing they disliked about their neighborhood.

Social environment variables accounted for $33.1 \%$ of the total dislike responses (not including outlier sites). This is not markedly different from the $40.1 \%$ accounted for by physical environment variables, especially considering that $14.9 \%$ of responses remain undistinguished in the other category.

For neighborhood factors that participants liked, family atmosphere, peace and quiet, friendly neighbors, and safety were considered part of the social environment, and appearance/cleanliness, nature, location, ease of transportation, physical quality, and lack of traffic were categorized as part of the physical environment (see Table 11). The most commonly reported neighborhood aspect that participants liked was the location (27.8\%; $44.7 \%$ for the two outlier sites). Location was further divided into access to stores and services, proximity to park, and proximity to family. Access to stores and services was by far the most commonly reported aspect of location that participants liked across all sites (see Table 11.1). After location, the second most commonly liked aspect about neighborhoods across all sites was ease of transportation (14.7\%; Table 11). With 
outliers removed, the second most commonly liked aspect about neighborhoods was friendly neighbors (13.6\% of responses; Table 11).

Aspects of the social environment accounted for $31.1 \%$ of liked neighborhood factors, and aspects of the physical environment accounted for $57.2 \%$. Similar to the disliked responses, the differences between categories may appear to be inflated because $9.3 \%$ of responses remain uncategorized in the other category. 


\section{Discussion}

The physical and social environments in which individuals live have the ability to shape community life through their influence on neighborhood experiences. Natural variations in communities (social, cultural, geographical, etc.) are the thread from which community life is woven; and individuals must be understood as being influenced by these processes (Maller, Townsend, Pryor et al., 2005; Bronfenbrenner, 1977; Kloos and Shah, 2009). These influences may be particularly important to individuals with psychiatric disabilities, as they have the potential to impact well-being and recovery outcomes (Kloos and Shah, 2009). The findings of this exploratory study illuminate some of the social and physical factors that may influence neighborhood satisfaction for individuals with psychiatric disabilities residing in supportive housing environments and suggest avenues for future research and intervention.

\section{Overview of Study Findings}

Gender differences. First, the preliminary covariate analyses in this study suggest that female participants experienced lower neighborhood satisfaction compared to male participants. Diener and Diener (1995) propose that one reason women may experience lower satisfaction in various domains in Western cultures (e.g., social relations, health, and finances) is because they possess less power and fewer resources than men. Although follow-up research is needed to further examine this finding, results of this study suggest that supportive housing services may need to focus particular attention on the neighborhood experiences of female residents to ensure that their levels of satisfaction are comparable to those of male residents. No differences in satisfaction 
were found by participant race, age, or diagnostic status, although this may be due to the specific environmental context of the present study.

Impacts of the social and physical neighborhood environment. Drawing upon the social ecological approach to studying housing environments suggested by Kloos and Shah (2009), the primary purpose of this study was to better understand the influence of social and physical environmental variables on neighborhood satisfaction for individuals with psychiatric disabilities. As hypothesized, the social environment predicted neighborhood satisfaction. Increased perceptions of safety and a positive social climate were associated with increased neighborhood satisfaction; that is, perceiving one's neighborhood as being safe and welcoming contributed to overall satisfaction with it as a place to live. Neighborhoods that are perceived as safe and accepting of individuals with mental illnesses may be particularly important to individuals with psychiatric disabilities living in supportive housing, as they are often acutely aware of the stigma associated with their diagnosis and housing complex.

Residents who lived in areas that were more diverse, as indicated by higher Diversity Index ratings, were less satisfied with their neighborhoods. One explanation may come from findings in the neighborhood literature that living among others who do not share one's culture or ethnicity can be a source of stress (Potter \& Cantarero, 2004). Again, this may be particularly true for individuals with psychiatric disabilities as they may already experience disconnection and misunderstanding from their neighbors due to stigma or problems adhering to social interaction norms when symptoms interfere with functioning. 
Another explanation may come from a methodological consideration for this

study. Diversity Index scores are calculated at the block group level, which can consist of anywhere from 300 to 6000 people, and may not necessarily constitute the same area that respondents were mentally referencing when they answered questions about their neighborhood. Therefore, the small but significant difference may be a methodological artifact of this study.

Perhaps the most likely explanation is that race and socioeconomic status are confounded because people of color disproportionately live in lower income neighborhoods with fewer resources (Swaroop \& Krysan, 2011; Sampson \& Raudenbusch, 2004). Therefore, the apparent negative influence of increased neighborhood diversity may actually be the negative influence of lower neighborhood socioeconomic status on neighborhood satisfaction. This would appear to be supported by the finding in this study that neighborhood diversity was significantly negatively correlated with objective physical quality and subjective safety - both factors that would be expected to be lower in neighborhoods with lower socioeconomic status. Ideally, a future study would include an analysis of the impact of socioeconomic status on neighborhood satisfaction to better understand the complex relationship between race/ ethnicity, SES, and satisfaction.

The neighborhood physical environment also positively predicted neighborhood satisfaction. In fact, subjective physical quality was the only variable that was significantly related to neighborhood satisfaction (walkability and researcher-rated or objective physical quality were not). This may be due in part to the fact that it was the 
only self-reported variable included in the model, while the other two variables were more objective indicators. Previous research suggests that self-reported variables are consistently better predictors of outcomes than objective variables (e.g., Stiffman et al., 1999; Townley \& Kloos, 2014). Thus, while researcher-rated physical quality on its own was significantly correlated with satisfaction, it is not surprising that it was no longer a significant predictor when analyzed concurrently with participant-reported neighborhood quality.

When social and physical environmental variables were examined collectively in the first hierarchical regression model (RQ1, Model 3), the physical environment variables failed to explain any significant amount of variance in satisfaction above and beyond the influence of the social environment. This was in line with study hypotheses and previous findings in the literature. However, after adding the gender covariate in the final block of the hierarchical regression, subjective neighborhood quality was the only remaining significant environmental predictor of neighborhood satisfaction. Thus, while social factors collectively accounted for more variance in neighborhood satisfaction than physical factors, neighborhood physical quality was the strongest individual predictor, such that higher perceptions of quality were associated with increased neighborhood satisfaction.

One explanation for this finding may come from expanding on Maslow's theory of human motivation, which posits that physiological needs for shelter take precedence over social and psychological needs (Maslow, 1943). While Maslow's definition of physiological needs was intended to capture basic survival needs (e.g., food, water, air, 
shelter), the principle may be extrapolated to the present study. That is, individuals are satisfied with their neighborhoods when they feel that their physical needs are met - for example, that they have access to health care, transportation, and grocery stores (items that are captured in the subjective physical quality scale).

Lastly, in looking at the individual items on the HES-NQ scale of neighborhood physical quality (see Appendix III), it becomes apparent that the scale captures many of the same constructs as the other scales included in this analysis. For example, individual items measure crime and police responsiveness (which is similar to subjective safety), sidewalk quality and access to neighborhood stores and services (similar to WalkScore), and proximity to family and friends (perhaps similar to relationships with neighbors or neighborhood social climate). Given that the scale taps into so many features hypothesized to impact individuals' experiences in and impressions of their living environments, it is not surprising that subjective neighborhood quality was the strongest predictor of neighborhood satisfaction in this study.

Finally, the finding that gender was a significant predictor of neighborhood satisfaction even after accounting for the influence of the environmental variables lends additional support to the importance of examining and intervening around aspects of neighborhoods that may contribute to lower neighborhood satisfaction among women compared to men. It may also be worthwhile to consider other individual-level factors that may impact neighborhood satisfaction, including socioeconomic status, nativity, previous neighborhoods of residence, and homeownership status. 
Objective versus subjective indicators. This study also sought to determine whether the construct of neighborhood satisfaction is best captured via measures of subjective experiences or objective features of the environment. In a hierarchical regression model assessing the influence of both subjective and objective environmental factors (RQ2, Model 4), subjective measures accounted for a moderate percentage of the variance in neighborhood satisfaction, with both subjective safety and neighborhood quality being significant predictors of satisfaction when they were entered into the model. In line with study hypotheses, after accounting for the influence of the subjective experiences, the objective environmental measures did not account for any significant additional variance, although the Diversity Index variable was significantly negatively associated with satisfaction. As in the results of the hierarchical regression discussed above, gender and subjective physical quality were significant predictors of satisfaction in the full model. While findings in this section generally support common reports in the literature that subjective environmental variables are more predictive of outcomes than objective variables, it must be acknowledged that common-method variance may partially explain this effect since the dependent variable in this study (neighborhood satisfaction) was also self-reported.

Qualitative findings. Findings from the qualitative component of this mixedmethods study help to triangulate the results discussed above. Specifically, the finding from the qualitative analyses that aspects of the physical environment accounted for $57 \%$ of liked neighborhood factors reported by participants while aspects of the social environment accounted for only $31 \%$ is related to the quantitative finding that subjective 
neighborhood physical quality was the strongest predictor of neighborhood satisfaction. In further support of this parallel finding across the two methods, the aspects of the neighborhoods that participants reported liking most frequently (i.e., location and access to stores and services, friendly neighbors, ease of transportation, and peace and quiet) are items that are also reflected in the subjective physical quality measure (e.g., I can get the things that I need from stores in my neighborhood and There is too much noise in my neighborhood; see Appendix III).

Residents reported liking being able to easily access stores and services in their neighborhoods and appreciating when their neighborhoods were quiet and peaceful. Similarly, residents disliked being unable to access stores and services and reported disliking various types of noise pollution in their neighborhoods. Residents also reported appreciating friendly neighbors, indicating that the neighborhood social environment was important to their overall satisfaction with the neighborhood. Another social environment factor that a small percentage of residents reported liking about their neighborhood was that it had a family atmosphere - that is, there were neighborhood children and the area seemed "family-oriented". This concept is not captured in the measures of neighborhood environments currently being used and may warrant further investigation as a contributing factor to neighborhood satisfaction.

For the two outlier sites that had significantly lower neighborhood satisfaction scores, the vast majority of disliked factors were social (e.g., crime). This is in keeping with the quantitative findings, which indicated that social environment factors collectively explained more variance in neighborhood satisfaction than physical factors. 
Therefore, it follows that the outlier sites would have lower overall neighborhood satisfaction since they perceived their social environment (particularly safety) in a negative light. In addition, residents at these two sites reported few positive social aspects; instead, the factors that were liked were primarily physical (e.g., location and availability of transportation).

Crime was the most commonly reported disliked neighborhood feature across all study sites. Similar to Newman (1994) who found that concerns about safety can overwhelm positive features of the neighborhood, residents who reported more concerns about safety and crime were less satisfied with their neighborhood overall. Residents were more satisfied with their neighborhoods when they perceived that they were of good physical quality and provided adequate access to needed stores and services. Therefore, it may be that to be satisfied with a neighborhood as a place to live, residents must first feel safe; beyond that basic (social) requirement, the physical features of the neighborhood may be the primary determinants of satisfaction.

\section{Limitations}

A few study limitations should be acknowledged in addition to those already noted above. First, one concern may be that symptomatology interfered with subjective ratings. For example, individuals with depressive disorders may have rated their satisfaction lower than others, or may have provided negative evaluations of their neighborhood physical and social environments. While it is possible that this occurred, the covariate analysis indicated that there were no differences in satisfaction ratings between individuals with mood disorders and those with thought disorders. In addition, 
the findings of this study are intended to be relevant to housing programs that house individuals with psychiatric disabilities, some of whom will experience depressive symptomatology. This study shows that the social and physical environment has the ability to influence neighborhood satisfaction, independent of diagnosis. A future study should assess other indicators of residents' response validity, including current medication adherence and mood or affect.

Generalizability in this study may be limited because it included a localized sample of residents living in a particular housing program. They may participate in or experience programs and organizational practices that are unique to the housing program or service organization, and which may not generalize to other settings or housing sites. In addition, there may be unique features of the urban Pacific Northwest neighborhoods from which these data were collected that may be quite different from other regions of the country.

Another possible limitation may be that participants evinced response bias due to the fact that survey data were collected via interview methodology. In a one-one-one setting in which the research assistant verbally asked the survey questions, participants may have felt pressure to manage their self-presentation, and so may have under-reported negative perceptions and over-reported positive perceptions. Although all efforts were made to ensure participants knew their identities and responses would be kept confidential, and that individual responses would not be shared with the housing staff, it is possible that participants gave positively biased responses out of concern of retaliation. Future studies might consider other methods of data collection to minimize these 
concerns, including having peers administer the survey, conducting interviews over the phone, or transporting participants to a location that is not affiliated with their housing program. Group interviews may also eliminate some of these concerns, as participants will see that their survey is just one of many being collected simultaneously, making it more difficult to identify individual participants from their responses. In addition, a possible confound is that participants experiencing a fluctuation in psychiatric symptoms may provide responses that are not representative of their usual level of functioning or perceptions.

Another consideration, as discussed above, is that the objective variables in this study were collected at varying levels of analysis (census tracts, block groups, address level, etc.). While this is unavoidable given the nature and availability of the data, it should be noted that data provided at one of these levels may not be relevant to a given individual's conceptualization and experience of their neighborhood.

The cross-sectional nature of the study design means that causality cannot be inferred. It is possible there are other factors at play that cause the association between neighborhood variables and neighborhood satisfaction that were not measured in this study. Perhaps less likely, the directionality between neighborhood satisfaction and neighborhood variables may be reversed such that the social and physical environment of the neighborhood is a product of neighborhood satisfaction. For example, residents who are satisfied with their neighborhood may take better care of the physical environment and do more to positively impact the social climate of the environment. 
Lastly, the measure of neighborhood satisfaction includes only two items. This likely does not capture the totality of what neighborhood satisfaction encompasses. The present study's exploration of the construct of neighborhood satisfaction is important because it provides a starting point for creating a more comprehensive measure of neighborhood satisfaction. Future research has the potential to contribute to this understanding.

\section{Implications for Research}

Neighborhoods are an increasingly important and relevant level of analysis to consider, particularly for public health interventions (Coulton, 2012). This study contributes practical methodological information about ways to measure and analyze neighborhood-level experiences from various data sources (e.g., individual perceptions, Census data, and WalkScore reports). Researchers are often faced with the question of whether to draw upon data from subjective or objective sources, and this study suggests that subjective measures may be more predictive of neighborhood satisfaction.

There may also be value in investigating the use of objective measures that are more proximal to individuals, or more relevant for individuals with psychiatric disabilities. For example, the measure of walkability calculates the availability of amenities within a quarter mile. Other studies have shown that individuals may only be willing to walk up to one-tenth of a mile to access services. In addition, it should be noted that many individuals with psychiatric disabilities also face physical health challenges, such as obesity and chronic pain, which may make walking to stores more challenging. Therefore, the measure of walkability used in this study may not be a relevant operational 
definition for individuals with psychiatric disabilities. In addition, not all of the amenities used in the WalkScore.com algorithm may be desired by members of this population. For example, a housing site that located close to bars, restaurants, and fitness centers might be awarded a relatively high WalkScore; however, residents with psychiatric disabilities often live on fixed incomes that leave little room to enjoy these luxuries. Similarly, the presence of neighborhood schools would improve the WalkScore but may have less relevance for members of this population who often do not have young children living with them. A future direction could be to work with individuals with psychiatric disabilities who live in supportive housing sites to design a measure of walkability that better reflects their needs, abilities, and desires.

Similarly, the use of the researcher-rated (objective) measure of neighborhood physical quality may be more reflective of actual neighborhood physical quality if it is completed by individuals who live in the area (for example, the supportive housing residents). They may be more attuned to the physical environment than researchers who do not engage with it on a daily basis. For example, residents may know where lessvisible graffiti is located, or areas where evidence of drug use is most likely to be seen. Another possibility to improve the use of this measure in the future may be to have the checklist completed multiple times for each neighborhood; for example, every day for a week or multiple times in a month. This may capture elements of neighborhood quality that fluctuate over time.

Another opportunity to improve the predictive ability of objective factors might be in the measurement of neighborhood crime. It may be that more sensitive measures of 
crime are needed than the data used in this study (which were available only at the census tract level). Technology innovations, such as phone applications that allow residents to report anything from potholes to graffiti, offer opportunities to obtain real-time geolocated information. Other measures of crime may be considered as operating somewhere between subjective and objective levels of measurement. For example, survey questions can ask residents to report actual instances of crime that have occurred (e.g., "have you or has anyone in your household been the victim of a crime in the past 30 days/if so, what was the crime?"). As many crimes often go unreported, a question such as this has the opportunity to capture crime that would not be available in objective sources (e.g., FBI data). It is also not as subjective as asking about general perceptions of safety, because it requires the participant to consider actual events.

This study uniquely combined mixed methods to generate a fuller understanding of neighborhood social and physical environments as they impact neighborhood satisfaction. In addition to measuring neighborhood satisfaction using a standard quantitative scale, residents were asked open-ended questions about aspects of their neighborhood that they like or dislike. Integrating results from these sources has the potential to generate new ways to understand and measure neighborhood satisfaction in future research. For example, although subjective physical quality was the best predictor of neighborhood satisfaction (along with gender), the measure itself includes questions about a variety of neighborhood components. Future studies should consider parsing the measure of neighborhood quality into component parts, perhaps organized by whether they are physical, social, objective and/or subjective variables. Unexpected findings from 
the qualitative analyses also illuminate potential features of neighborhoods that should be examined more closely in future research, including the presence of non-residents who are perceived as increasing levels of crime or other deviant behaviors.

\section{Implications for Practice}

This study contributes a needed analysis of neighborhood-level predictors to the growing body of literature on resident satisfaction. Neighborhood-level factors are likely more important to individual outcomes for people with psychiatric disabilities (Metraux et al, 2012), yet most studies of this population focus primarily on housing-level factors. The role that physical and social context plays in residents' neighborhood satisfaction has important implications for housing interventions. Programs seeking to locate neighborhoods for new housing developments should consider the importance of the physical and social environment to neighborhood satisfaction, particularly in light of the potential implications for resident tenure and well-being outcomes that have been noted in the literature (e.g., Metraux et al, 2012; Kloos and Shah, 2009; Tsemberis et al., 2003). Extant housing sites should monitor resident perceptions of the neighborhood, particularly the social environment. In particular, housing programs should be aware of perceptions of neighborhood safety, as this appears to be particularly detrimental to residents' neighborhood satisfaction.

If residents are dissatisfied with the neighborhood, housing programs may consider implementing interventions to improve social relationships between residents and the surrounding neighborhood. If crime is a problem in the neighborhood, residents could be offered the opportunity to engage in pro-active problem solving, such as 
forming a neighborhood watch. Interventions to increase police presence should also be considered. When locating new housing sites, programs should take into account the availability of stores and services nearby. Regular and readily available public transportation routes are particularly important, given that many individuals with psychiatric disabilities rely on public transportation to meet their daily needs. Extant housing programs should consider monitoring the local business climate and, where possible, become involved in neighborhood decisions regarding the development or placement of shopping centers (for example, by attending neighborhood meetings). Availability of stores and services is a key component in neighborhood quality, and thus important to overall neighborhood satisfaction.

\section{Conclusions}

This mixed-methods study examined physical and social environmental factors that impact the neighborhood satisfaction of individuals with psychiatric disabilities to inform future research and interventions aimed at enhancing satisfaction. Studies of housing and neighborhood environments for individuals with psychiatric disabilities remain important vehicles for change. It is through research in this area that policy and practice has begun to shift toward housing that protects and promotes the rights of individuals. Recognizing the importance of this progress, the Convention on the Rights of Persons with Disabilities stipulated that individuals have the right not only to housing that is adequate and conducive to well-being, but also to the "continuous improvement of living conditions" (2006; Article 28.1). 


\section{References}

Aron, A., \& Aron, E. (1999). Statistics for psychology (2 ed.). Upper Saddle River, NJ: Prentice Hall.

Baker, F., \& Douglas, C. (1990). Housing environments and community adjustment of severely mentally ill persons. Community Mental Health Journal,26(6), 497-505.

Beal, G., Veldhorst, G., McGrath, J. L., Guruge, S., Grewal, P., DiNunzio, R., \& Trimnell, J. (2005). Constituting community: Creating a place for oneself. Psychiatry, 68(3), 199-211.

Braun, V., \& Clarke, V. (2006). Using thematic analysis in psychology. Qualitative Research in Psychology, 3(2), 77-101.

Bronfenbrenner, U. (1977). Toward an experimental ecology of human development. American Psychologist, 32(7), 513.

Bruin, M.J., \& Cook, C.C. (1997). Understanding constraints and residential satisfaction among low-income single-parent families. Environment and Behavior, 29, $532-$ 553.

Brusilovskiy, E., \& Salzer, M. S. (2012). A study of environmental influences on the well-being of individuals with psychiatric disabilities in Philadelphia, PA. Social Science \& Medicine, 74(10), 1591-1601.

Byrne, T., Munley, E. A., Fargo, J. D., Montgomery, A. E., \& Culhane, D. P. (2013). New perspectives on community-level determinants of homelessness. Journal of Urban Affairs, 35(5), 607-625. 
Campbell, A. (1976). Subjective measures of well-being. American Psychologist, 31(2), 117.

Carling, P. J. (1995). Return to community: Building support systems for people with psychiatric disabilities. Guilford Press.

Carr, L. J., Dunsiger, S. I., \& Marcus, B. H. (2010). Walk score ${ }^{\mathrm{TM}}$ as a global estimate of neighborhood walkability. American Journal of Preventive Medicine, 39(5), 460463.

Castellow, J., Kloos, B., \& Townley, G. (in press). Previous homelessness as a risk factor for recovery from serious mental illness. Community Mental Health Journal.

Chan, D. V., Helfrich, C. A., Hursh, N. C., Rogers, E. S., \& Gopal, S. (2014). Measuring community integration using Geographic Information Systems (GIS) and participatory mapping for people who were once homeless. Health \& Place, 27, 92-101.

Coulton, C. (2012). Defining neighborhoods for research and policy. Cityscape, 231-236.

Crooks, V. A., Schuurman, N., Cinnamon, J., Castleden, H., \& Johnston, R. (2010). Refining a location analysis model using a mixed methods approach: Community readiness as a key factor in siting rural palliative care services. Journal of Mixed Methods Research, 1558689810385693.

Cutrona, C., Russell, D., Brown, P., Clark, L., Hessling, R., \& Gardner, K. (2005). Neighborhood context, personality, and stressful life events as predictors of depression among African American women. Journal of Abnormal Psychology, $114,3 \mathrm{e} 15$. 
Diener, E., \& Diener, M. (1995). Cross-cultural correlates of life satisfaction and selfesteem. Journal of Personality and Social Psychology, 68(4), 653-663.

Dittmar, H., \& Poticha, S. (2004). Defining transit-oriented development: The new regional building block. The new transit town: Best practices in transit-oriented development, 20-55.

Doyle, S., Kelly-Schwartz, A., Schlossberg, M., \& Stockard, J. (2006). Active community environments and health: the relationship of walkable and safe communities to individual health. Journal of the American Planning Association, 72(1), 19-31.

Foster, S., \& Giles-Corti, B. (2008). The built environment, neighborhood crime and constrained physical activity: an exploration of inconsistent findings. Preventive Medicine, 47(3), 241-251.

Friedman, D.J., Hunter, E. L., \& Parrish, R. G. (2002). Shaping a vision of health statistics for the $21^{\text {st }}$ century. Washington, DC: Department of Health and Human Services Data Council, Centers for Disease Control and Prevention, National Center for Health Statistics, and National Committee on Vital and Health Statistics, 2002. Available at: http://www.ncvhs.hhs.gov/hsvision/. Accessed October 25, 2015.

Hair, J. F., Black, W. C., Babin, B. J., Anderson, R. E., \& Tatham, R. L. (2006). Multivariate data analysis. Prentice Hall Pearson Education. 
Harkness, J., Newman, S. J., \& Salkever, D. (2004). The Cost-Effectiveness of Independent Housing for the Chronically Mentally Ill: Do Housing and Neighborhood Features Matter?. Health Services Research, 39(5), 1341-1360.

Hartman, C. (2006). 8 The Case for a Right to Housing. A right to housing: Foundation for a new social agenda, 177.

Hill, T., Ross, C., \& Angel, R. (2005). Neighborhood disorder, psychophysiological distress, and health. Journal of Health \& Social Behavior, 46, 170e186.

Kang, N., \& Kwak, N. (2003). A Multilevel Approach to Civic Participation Individual Length of Residence, Neighborhood Residential Stability, and Their Interactive Effects With Media Use. Communication Research, 30(1), 80-106.

Kessler, R. C., Berglund, P. A., Bruce, M. L., Koch, J. R., Laska, E. M., Leaf, P. J., ... \& Wang, P. S. (2001). The prevalence and correlates of untreated serious mental illness. Health Services Research, 36(6 Pt 1), 987.

Kline, R. (2011). Principles and practice of structural equation modeling ( $3^{\text {rd }}$ edition). New York: Guilford Press.

Kloos, B., \& Shah, S. (2009). A social ecological approach to investigating relationships between housing and adaptive functioning for persons with serious mental illness. American Journal of Community Psychology, 44(3-4), 316-326.

Kloos, B., \& Townley, G. (2011). Investigating the relationship between neighborhood experiences and psychiatric distress for individuals with serious mental illness. Administration and Policy in Mental Health and Mental Health Services Research, 38(2), 105-116. 
Krieger, N. (2006). A century of census tracts: Health and the body politic (19062006). Journal of Urban Health, 83(3), 355-361.

Kruger, D. J., Reischl, T. M., \& Gee, G. C. (2007). Neighborhood social conditions mediate the association between physical deterioration and mental health. American Journal of Community Psychology, 40(3-4), 261-271.

Leyden, K. M. (2003). Social capital and the built environment: the importance of walkable neighborhoods. American Journal of Public Health, 93(9), 1546-1551.

Lombard, M., Snyder-Duch, J., \& Bracken, C. C. (2002). Content analysis in mass communication: Assessment and reporting of intercoder reliability. Human Communication Research, 28, 587-604.

Lewin, K. (1939). Field theory and experiment in social psychology: Concepts and methods. American Journal of Sociology, 868-896.

Link, B. G., Struening, E. L., Neese-Todd, S., Asmussen, S., \& Phelan, J. C. (2014). Stigma as a barrier to recovery: The consequences of stigma for the self-esteem of people with mental illnesses. Psychiatric Services.

Lombard, M., Snyder-Duch, J., \& Bracken, C. C. (2010, June 1). Practical Resources for Assessing and Reporting Intercoder Reliability in Content Analysis Research Projects. Retrieved May 12, 2015 from http://matthewlombard.com/reliability/\#How should content analysis researchers properly assess and report intercoder reliability 
Maller, C., Townsend, M., Pryor, A., Brown, P., \& St Leger, L. (2005). Healthy nature healthy people: 'contact with nature' as an upstream health promotion intervention for populations. Health Promotion International, 21(1), 45-54.

Maslow, A. H. (1943). A theory of human motivation. Psychological Review, 50(4), 370396.

Metraux, S., Brusilovskiy, E., Prvu-Bettger, J. A., Wong, Y. L. I., \& Salzer, M. S. (2012). Geographic access to and availability of community resources for persons diagnosed with severe mental illness in Philadelphia, USA. Health \& Place, 18(3), 621-629.

McGregor, B. (2008). The Social Ecology of Support in Supportive Housing and Its Relationship to Psychological Distress and Well-being. ProQuest.

McDaniel, J. M. (2008). Examining contextually-based correlates of perceived social support in the supported housing environment. Unpublished master's thesis.

McGregor, B. S. (2008). The social ecology of support in supportive housing and its impact on psychological distress \& well-being. Unpublished dissertation.

Morgan, D. L. (1998). Practical strategies for combining qualitative and quantitative methods: Applications to health research. Qualitative Health Research, 8(3), 362376.

Morgan, D. L. (2013). Integrating qualitative and quantitative methods: A pragmatic approach. Sage publications. 
Moudon, A. V., Lee, C., Cheadle, A. D., Garvin, C., Johnson, D., Schmid, T. L., ... \& Lin, L. (2006). Operational definitions of walkable neighborhood: theoretical and empirical insights. Journal of Physical Activity \& Health, 3, S99.

Mueser, K. T., Bond, G. R., Drake, R. E., \& Resnick, S. G. (1998). Models of community care for severe mental illness: a review of research on case management. Schizophrenia Bulletin, 24(1), 37-74.

Murray, C., \& Lopez, A. E. (1996). The global burden of disease: A comprehensive assessment of mortality and disability for disease, injuries and risk factors in 1990 and projected to 2020. Harvard University: Harvard School of Public Health on behalf of the World Health Organisation and the World Bank.

Newman, S. J. (1994). The housing and neighborhood conditions of persons with severe mental illness. Hospital and Community Psychiatry, 45(4), 338-343.

Newman, S. J. (2001). Housing attributes and serious mental illness: Implications for research and practice. Psychiatric Services, 52(10), 1309-1317.

Oishi, S. (2010). The psychology of residential mobility implications for the self, social relationships, and well-being. Perspectives on Psychological Science,5(1), 5-21.

Oishi, S., Rothman, A. J., Snyder, M., Su, J., Zehm, K., Hertel, A. W., ... \& Sherman, G. D. (2007). The socioecological model of procommunity action: the benefits of residential stability. Journal of Personality and Social Psychology, 93(5), 831.

Pescosolido, B. A., Martin, J. K., Long, J. S., Medina, T. R., Phelan, J. C., \& Link, B. G. (2010). “A disease like any other"? A decade of change in public reactions to 
UNDERSTANDING NEIGHBORHOOD SATISFACTION

schizophrenia, depression, and alcohol dependence. American Journal of Psychiatry.

Piro, F. N., Nœess, Ø., \& Claussen, B. (2006). Physical activity among elderly people in a city population: the influence of neighbourhood level violence and self perceived safety. Journal of Epidemiology and Community Health, 60(7), 626-632.

Potter, J., \& Cantarero, R. (2006). How does increasing population and diversity affect resident satisfaction? A small community case study. Environment and Behavior, 38(5), 605-625.

R Core Team (2013). R: A language and environment for statistical computing. $R$ Foundation for Statistical Computing, Vienna, Austria. URL http://www.Rproject.org/.

Raphael, B., Schmolke, M., \& Wooding, S. (2005). Links between mental and physical health and illness. In H. Herrman, S. Saxena, \& R. Moodie (Eds.), Promoting mental health: Concepts, emerging evidence, practice: Report of the World Health Organization. Geneva: World Health Organization.

Reese-Cassal, K. (2014). 2014/2019 Esri Diversity Index. Esri, Redlands, California, USA.

Rose, R. (2000). How much does social capital add to individual health?: a survey study of Russians. Social Science \& Medicine, 51, 1421e1435.

Rüsch, N., Müller, M., Lay, B., Corrigan, P. W., Zahn, R., Schönenberger, T., ... \& Rössler, W. (2014). Emotional reactions to involuntary psychiatric hospitalization 
UNDERSTANDING NEIGHBORHOOD SATISFACTION

and stigma-related stress among people with mental illness. European Archives of Psychiatry and Clinical Neuroscience, 264(1), 35-43.

Sampson, R. J., \& Raudenbush, S. W. (2004). Seeing disorder: neighborhood stigma and the social construction of 'Broken Windows.' Social Psychology Quarterly 67 (4): 319-342.

Sarason, S. B. (1974). The psychological sense of community: Prospects for a community psychology. Jossey-Bass.

Silver, E., Mulvey, E., \& Swanson, J. (2002). Neighborhood structural characteristics and mental disorder: Faris and Dunham revisited. Social Science \& Medicine, 55, $1457 \mathrm{e} 1470$.

Soper, D.S. (2016). Post-hoc Statistical Power Calculator for Multiple Regression [Software]. Available from http://www.danielsoper.com/statcalc.

Srebnik, D., Livingston, J., Gordon, L., \& King, D. (1995). Housing choice and community success for individuals with serious and persistent mental illness. Community Mental Health Journal, 31(2), 139-152.

Stiffman AR, Hadley-Ives E, Elze D, Johnson S, Dore P (1999). Impact of environment on adolescent mental health and behavior: Structural equation modeling. American Journal of Orthopsychiatry. 69(1):73-86. [PubMed: 9990438]

Swaroop, S., \& Krysan, M. (2011). The determinants of neighborhood satisfaction: Racial proxy revisited. Demography, 48(3), 1203-1229.

Thornicroft, G., Alem, A., Santos, R. A., Barley, E., Drake, R. E., Gregorio, G., ... \& Wondimagegn, D. (2010). WPA guidance on steps, obstacles and mistakes to 
avoid in the implementation of community mental health care. World Psychiatry, 9(2), 67-77.

Townley, G. (2012). Networks of Community Support: Examining Community Integration of Individuals with Psychiatric Disabilities Residing in Supported and Non-Supported Housing. Unpublished dissertation chapter.

Townley, G., \& Kloos, B. (2014). Mind over matter? The role of individual perceptions in understanding the social ecology of housing environments for individuals with psychiatric disabilities. American Journal of Community Psychology, 54(3-4), 205-218.

Townley, G., Miller, H., \& Kloos, B. (2013). A little goes a long way: The impact of distal social support on community integration and recovery of individuals with psychiatric disabilities. American Journal of Community Psychology, 52(1-2), 8496.

Tsemberis, S., Rogers, E. S., Rodis, E., Dushuttle, P., \& Skryha, V. (2003). Housing satisfaction for persons with psychiatric disabilities. Journal of Community Psychology, 31(6), 581-590.

Tsemberis, S., Kent, D., \& Respress, C. (2012). Housing stability and recovery among chronically homeless persons with co-occuring disorders in Washington, DC. American Journal of Public Health, 102(1), 13-16.

United Nations General Assembly (1948). Universal declaration of human rights. Article 25. Retrieved September 15, 2015 from http://www.un.org/en/documents/udhr/ 
United Nations General Assembly (2006). Convention on the rights of persons with disabilities. Retrieved October 28, 2015 from http://www.un.org/disabilities/convention/conventionfull.shtml

United States Census Bureau (2012). Geographic terms and concepts - Census tract. Retrieved October 25, 2015 from https://www.census.gov/geo/reference/gtc/gtc_ct.html.

van Lenthe, F. J., Brug, J., \& Mackenbach, J. P. (2005). Neighbourhood inequalities in physical inactivity: the role of neighbourhood attractiveness, proximity to local facilities and safety in the Netherlands. Social Science \& Medicine, 60(4), 763775.

Weidemann, S., Anderson, J. R., Butterfield, D. I., \& O'Donnell, P. M. (1982). Residents' Perceptions of Satisfaction and Safety A Basis for Change in Multifamily Housing. Environment and Behavior, 14(6), 695-724.

Weinstein Agrawal, A., Schlossberg, M., \& Irvin, K. (2008). How far, by which route and why? A spatial analysis of pedestrian preference. Journal of Urban Design, 13(1), 81-98.

White, M., Kasl, S., Zahner, G. E. P., Will, J. C. (1987). Perceived crime in the neighborhood and mental health of women and children. Environment and Behavior, 19(5):588-613.

White, G. W., Simpson, J. L., Gonda, C., Ravesloot, C., \& Coble, Z. (2010). Moving from independence to interdependence: a conceptual model for better 
understanding community participation of centers for independent living consumers. Journal of Disability Policy Studies, 20(4), 233-240.

WHO. (2004). Prevention of mental disorders: Effective interventions and policy options. Geneva: World Health Organisation. (Summary report).

Wilkerson, A., Carlson, N. E., Yen, I. H., \& Michael, Y. L. (2012). Neighborhood Physical Features and Relationships With Neighbors Does Positive Physical Environment Increase Neighborliness?. Environment and Behavior, 44(5), 595615.

Wong, Y. L. I., \& Solomon, P. L. (2002). Community integration of persons with psychiatric disabilities in supportive independent housing: A conceptual model and methodological considerations. Mental Health Services Research, 4(1), 1328.

Wong, Y. L. I., \& Stanhope, V. (2009). Conceptualizing community: A comparison of neighborhood characteristics of supportive housing for persons with psychiatric and developmental disabilities. Social Science \& Medicine, 68(8), 1376-1387.

Wright, P. A., \& Kloos, B. (2007). Housing environment and mental health outcomes: A levels of analysis perspective. Journal of Environmental Psychology, 27(1), 7989.

Yanos, P.T., Barrow, S.M., Tsemberis, S., 2004. Community integration in the early phase of housing among homeless persons diagnosed with severe mental illness: success and challenges. Community Mental Health Journal, 40, 133-150. 
Yanos, P. T., Felton, B. J., Tsemberis, S., \& Frye, V. A. (2007). Exploring the role of housing type, neighborhood characteristics, and lifestyle factors in the community integration of formerly homeless persons diagnosed with mental illness. Journal of Mental Health, 16(6), 703-717.

Zeldin, S., \& Topitzes, D. (2002). Neighborhood experiences, community connection, and positive beliefs about adolescents among urban adults and youth. Journal of Community Psychology, 30(6), 647-669.

Ziersch, A. M., Baum, F. E., MacDougall, C., \& Putland, C. (2005). Neighbourhood life and social capital: the implications for health. Social Science \& Medicine, 60(1), $71-86$. 


\section{Appendix I. Figures}

Figure 1. Neighborhood satisfaction predicted by neighborhood social and physical environment factors.

Social Environment Factors

- Safety (HES-S)

- Social Climate (HES-NSC)

- Neighbor Relations (HESNBR)

- Crime Reports

- Diversity Index Score

Physical Environment Factors

- Subjective Physical Quality (HES-NQ)

- Walk Score

- Objective Physical Quality (HERS-NQ) 
Figure 2. Neighborhood satisfaction predicted by subjective and objective neighborhood factors.

Subjective Factors

- Safety (HES-S)

- Neighborhood Social Climate (HES-NSC)

- Neighbor Relations (HESNBR)

- Physical Quality (HES-NQ)

$\quad$ Objective Factors
- Crime Reports
- Diversity Index Score
- Walk Score
- Physical Quality (HERS-NQ)

Neighborhood Satisfaction 
Figure 3. Map of supportive housing sites.

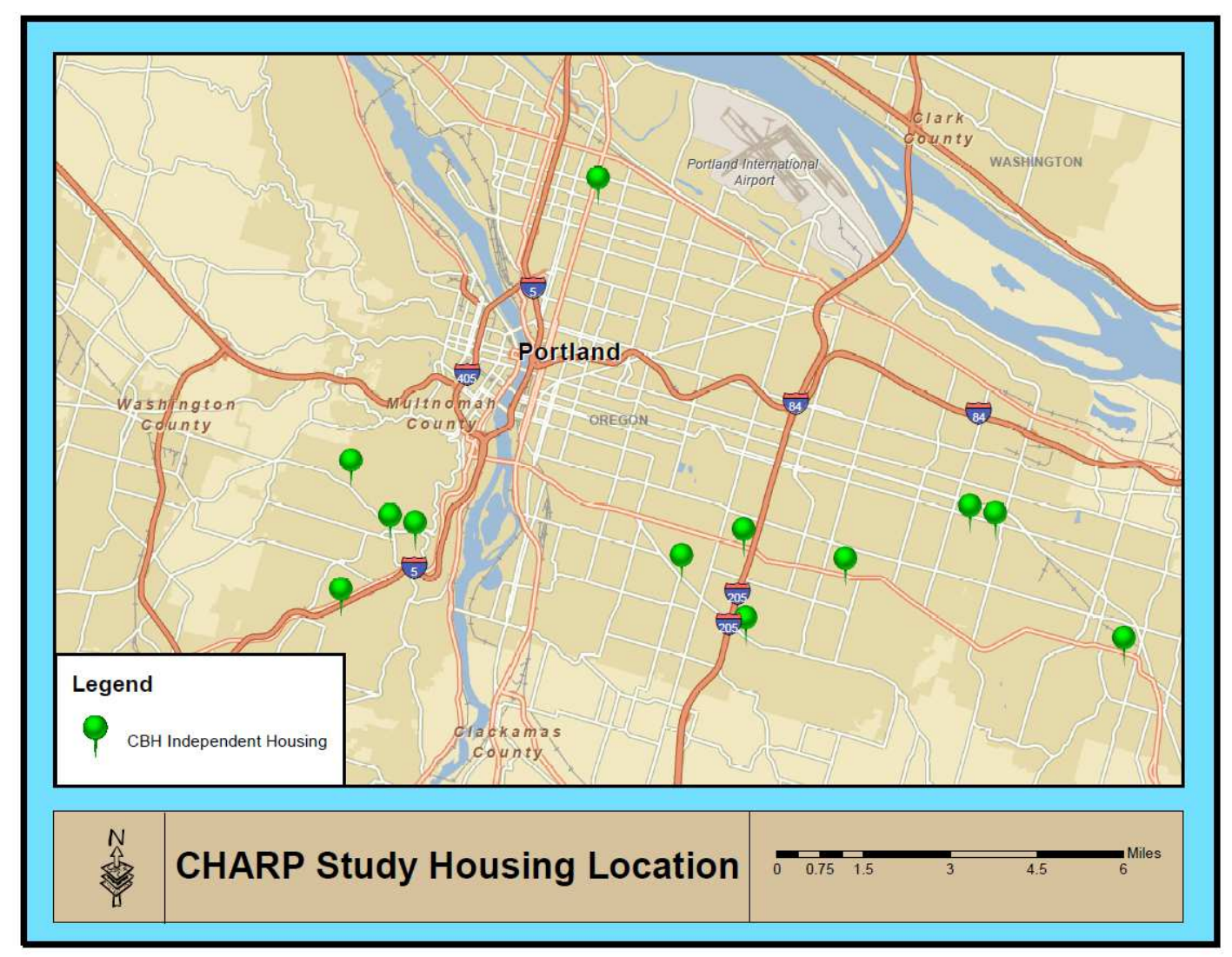




\section{Appendix II. Tables}

Table 1.

Descriptive Statistics.

\begin{tabular}{cccccccccc}
\hline \multirow{2}{*}{ Measure } & \multirow{2}{*}{$\mathrm{N}$} & Min & Max & Mean & SD & \multicolumn{2}{c}{ Skewness } & \multicolumn{2}{c}{ Kurtosis } \\
Neighborhood & & & & & & & & & \\
Satisfaction & 143 & 1.00 & 3.00 & 2.55 & .45 & -1.21 & .20 & .80 & .40 \\
Physical Quality & 143 & 1.50 & 5.00 & 3.51 & .53 & -.26 & .20 & 1.35 & .40 \\
Social Climate & 143 & 1.83 & 5.00 & 3.72 & .59 & -.25 & .20 & .60 & .40 \\
Relationships with & & & & & & & & & \\
Neighbors & 143 & 1.44 & 5.00 & 3.48 & .80 & -.22 & .20 & -.52 & .40 \\
Subjective Safety & 143 & 1.00 & 6.00 & 4.61 & 1.19 & -.81 & .20 & .19 & .40 \\
Diversity Index & 143 & .00 & 82.30 & 62.08 & 22.84 & -1.24 & .20 & .51 & .40 \\
WalkScore & 143 & 41.00 & 89.00 & 69.11 & 10.01 & .16 & .20 & .66 & .40 \\
Objective & & & & & & & & & \\
Physical Quality & 143 & 10.00 & 18.00 & 13.36 & 2.30 & .05 & .20 & -.79 & .40 \\
Crime Reports & 143 & 38.39 & 118.49 & 62.45 & 18.64 & 1.38 & .20 & 2.81 & .40 \\
\hline
\end{tabular}


Table 2.

Correlation Matrix of Study Variables.

\begin{tabular}{|c|c|c|c|c|c|c|c|c|c|}
\hline & \multicolumn{4}{|c|}{ Subjective } & \multicolumn{5}{|c|}{ Objective } \\
\hline & $\begin{array}{l}\text { Neighborhood } \\
\text { Satisfaction }\end{array}$ & $\begin{array}{l}\text { Physical } \\
\text { Quality }\end{array}$ & $\begin{array}{c}\text { Social } \\
\text { Climate }\end{array}$ & $\begin{array}{l}\text { Neighbor } \\
\text { Relations }\end{array}$ & $\begin{array}{c}\text { Subjective } \\
\text { Safety }\end{array}$ & $\begin{array}{l}\text { Crime } \\
\text { Reports }\end{array}$ & $\begin{array}{c}\text { Physical } \\
\text { Quality }\end{array}$ & $\begin{array}{l}\text { Diversity } \\
\text { Index }\end{array}$ & $\begin{array}{l}\text { Walk } \\
\text { Score }\end{array}$ \\
\hline $\begin{array}{l}\text { Neighborhood } \\
\text { Satisfaction }\end{array}$ & -- & & & & & & & & \\
\hline $\begin{array}{l}\text { Subjective } \\
\text { Physical } \\
\text { Quality }\end{array}$ & $.42^{* *}$ & & & & & & & & \\
\hline Social Climate & $.37^{* *}$ & $.63^{* *}$ & & & & & & & \\
\hline $\begin{array}{l}\text { Neighbor } \\
\text { Relations }\end{array}$ & $.23^{*}$ & $.37^{* *}$ & $.38^{* *}$ & & & & & & \\
\hline $\begin{array}{l}\text { Subjective } \\
\text { Safety }\end{array}$ & $.33^{* *}$ & $.41^{* *}$ & $.37^{* *}$ & .084 & & & & & \\
\hline Crime Reports & $.17^{*}$ & $.19^{*}$ & .16 & $.156^{*}$ & -.09 & & & & \\
\hline $\begin{array}{l}\text { Objective } \\
\text { Physical } \\
\text { Quality }\end{array}$ & $.22 * *$ & $.23^{* *}$ & .13 & -.061 & $.26^{* *}$ & $.43^{* *}$ & & & \\
\hline $\begin{array}{l}\text { Diversity } \\
\text { Index }\end{array}$ & $-.24^{* *}$ & -.11 & -.07 & .074 & $-.38^{* *}$ & .08 & $-.52^{* *}$ & & \\
\hline WalkScore & .07 & .11 & .127 & .09 & .05 & $.34^{* *}$ & .14 & -.16 & -- \\
\hline
\end{tabular}

Note. ${ }^{* *}$ Correlation is significant at the 0.01 level (2-tailed). ${ }^{*}$ Correlation is significant at the 0.05 level (2-tailed). 
Table 3.

Independent Samples T-Test: Neighborhood Satisfaction by Gender

\begin{tabular}{|c|c|c|c|c|c|c|c|c|c|c|}
\hline & \multicolumn{3}{|c|}{ Female } & \multicolumn{3}{|c|}{ Male } & \multirow[b]{2}{*}{$\mathrm{t}$} & \multirow[b]{2}{*}{$\mathrm{df}$} & \multicolumn{2}{|c|}{$95 \% \mathrm{CI}$} \\
\hline & $\mathrm{M}$ & $\mathrm{SD}$ & $\mathrm{n}$ & $\mathrm{M}$ & SD & $\mathrm{n}$ & & & Lower & Upper \\
\hline $\begin{array}{l}\text { Neighborhood } \\
\text { Satisfaction }\end{array}$ & 2.42 & .48 & 59 & 2.64 & .42 & 84 & $-2.92 *$ & 141 & -.38 & -.07 \\
\hline
\end{tabular}

Note. ${ }^{*} p<.05$ 
UNDERSTANDING NEIGHBORHOOD SATISFACTION

Table 4.

Linear Regression of Social Environment Variables Predicting Neighborhood

Satisfaction.

\begin{tabular}{|c|c|c|c|c|c|}
\hline \multirow{2}{*}{ Variable } & \multicolumn{3}{|c|}{ Model 1} & \multirow[b]{2}{*}{$\mathrm{t}$} & \multirow[b]{2}{*}{$\mathrm{p}$} \\
\hline & B & SE & $\beta$ & & \\
\hline (Constant) & 1.34 & .28 & & 4.78 & .00 \\
\hline Subjective Safety & .07 & .03 & .19 & 2.13 & .04 \\
\hline Crime Reports & .003 & .002 & .14 & 1.84 & .07 \\
\hline Social Climate & .17 & .07 & .23 & 2.57 & .01 \\
\hline Neighbor Relations & .07 & .05 & .12 & 1.45 & .15 \\
\hline Diversity Index & -.004 & .002 & -.18 & -2.21 & .03 \\
\hline
\end{tabular}

Note. $R=.49 ; R^{2}=.24, p<.001$. 
Table 5.

Linear Regression of Physical Environment Variables Predicting Neighborhood

Satisfaction.

\begin{tabular}{|c|c|c|c|c|c|}
\hline \multirow{2}{*}{ Variable } & \multicolumn{3}{|c|}{ Model 2} & \multirow[b]{2}{*}{$\mathrm{t}$} & \multirow[b]{2}{*}{$\mathrm{p}$} \\
\hline & B & SE & $\beta$ & & \\
\hline (Constant) & 1.02 & .34 & & 3.01 & .003 \\
\hline Subjective Physical Quality & .33 & .07 & .39 & 4.921 & .00 \\
\hline Objective Physical Quality & .03 & .02 & .13 & 1.618 & .11 \\
\hline WalkScore & .001 & .003 & .01 & .155 & .88 \\
\hline
\end{tabular}


Table 6.

Hierarchical Linear Regression of Social and Physical Environment Variables

Predicting Neighborhood Satisfaction.

\begin{tabular}{|c|c|c|c|c|c|}
\hline Variable & $\mathrm{B}$ & SE & $\beta$ & $\mathrm{R}^{2}$ & $\Delta \mathrm{R}^{2}$ \\
\hline Block 1 & & & & .24 & $.24 * * *$ \\
\hline (Constant) & 1.35 & .28 & & & \\
\hline Subjective Safety & .07 & .03 & $.17^{*}$ & & \\
\hline Crime Reports & .003 & .002 & .14 & & \\
\hline Social Climate & .17 & .07 & $.23 *$ & & \\
\hline Neighbor Relations & .07 & .05 & .12 & & \\
\hline Diversity Index & -.004 & .002 & $-.18^{*}$ & & \\
\hline Block 2 & & & & .27 & .03 \\
\hline (Constant) & 1.45 & .47 & & & \\
\hline Subjective Safety & .06 & .04 & .14 & & \\
\hline Crime Reports & .004 & .002 & .16 & & \\
\hline Social Climate & .10 & .08 & .13 & & \\
\hline Neighbor Relations & .04 & .05 & .08 & & \\
\hline Diversity Index & -.004 & .002 & $-.21^{*}$ & & \\
\hline Subjective Physical Quality & .19 & .09 & $.22 *$ & & \\
\hline Objective Physical Quality & -.01 & .02 & -.05 & & \\
\hline WalkScore & -.002 & .004 & -.05 & & \\
\hline Block 3 (Model 3) & & & & .29 & $.03 *$ \\
\hline (Constant) & 1.50 & .47 & & & \\
\hline Subjective Safety & .04 & .04 & .12 & & \\
\hline Crime Reports & .004 & .002 & .18 & & \\
\hline Social Climate & .09 & .08 & .12 & & \\
\hline Neighbor Relations & .04 & .05 & .06 & & \\
\hline Diversity Index & -.003 & .002 & -.17 & & \\
\hline Subjective Physical Quality & .19 & .09 & $.23^{*}$ & & \\
\hline Objective Physical Quality & -.008 & .02 & -.04 & & \\
\hline WalkScore & -.003 & .004 & -.06 & & \\
\hline Gender & -.16 & .07 & $-.17 *$ & & \\
\hline
\end{tabular}


UNDERSTANDING NEIGHBORHOOD SATISFACTION

Table 7.

Hierarchical Linear Regression of Subjective and Objective Environment Measures

Predicting Neighborhood Satisfaction.

\begin{tabular}{|c|c|c|c|c|c|}
\hline Variable & $\mathrm{B}$ & SE & $\beta$ & $\mathrm{R}^{2}$ & $\Delta \mathrm{R}^{2}$ \\
\hline Block 1 & & & & .23 & $.23 * * *$ \\
\hline (Constant) & 1.01 & .25 & & & \\
\hline Neighbor Relations & .04 & .05 & .08 & & \\
\hline Subjective Safety & .07 & .03 & $.18^{*}$ & & \\
\hline Social Climate & .10 & .08 & .13 & & \\
\hline Subjective Physical Quality & .20 & .09 & $.23^{*}$ & & \\
\hline Block 2 & & & & .27 & .04 \\
\hline (Constant) & 1.45 & .47 & & & \\
\hline Neighbor Relations & .04 & .05 & .08 & & \\
\hline Subjective Safety & .06 & .04 & .14 & & \\
\hline Social Climate & .10 & .08 & .13 & & \\
\hline Subjective Physical Quality & .19 & .09 & $.28^{*}$ & & \\
\hline Objective Physical Quality & -.01 & .02 & -.05 & & \\
\hline WalkScore & -.002 & .004 & -.05 & & \\
\hline Crime Reports & .004 & .002 & .16 & & \\
\hline Diversity Index & -.004 & .002 & $-.21 *$ & & \\
\hline Block 3 (Model 4) & & & & .29 & $.03 *$ \\
\hline (Constant) & 1.50 & .47 & & & \\
\hline Neighbor Relations & .04 & .05 & .06 & & \\
\hline Subjective Safety & .04 & .04 & .16 & & \\
\hline Social Climate & .09 & .08 & .12 & & \\
\hline Subjective Physical Quality & .19 & .09 & $.23 *$ & & \\
\hline Objective Physical Quality & -.01 & .02 & -.04 & & \\
\hline Walkscore & -.003 & .004 & -.06 & & \\
\hline Crime Reports & .004 & .002 & .18 & & \\
\hline Diversity Index & -.003 & .002 & -.17 & & \\
\hline Gender & -.16 & .07 & $-.17 *$ & & \\
\hline
\end{tabular}


Table 8.

Codebookfor "Dislike” Responses.

\begin{tabular}{|c|c|c|}
\hline Theme & Subtheme & Description \\
\hline \multirow[t]{6}{*}{ Crime } & gangs & $\begin{array}{l}\text { Specific mention of gangs; when gangs and } \\
\text { violence mentioned together, coded as gangs }\end{array}$ \\
\hline & drug use & $\begin{array}{l}\text { E.g., proximity to methadone clinic; drug or } \\
\text { marijuana use; public intoxication; "meth lab in } \\
\text { building" }\end{array}$ \\
\hline & violence & Physical fights; violence; shootings \\
\hline & property & $\begin{array}{l}\text { E.g., graffiti; car break-ins; theft; vandalism; } \\
\text { property damage }\end{array}$ \\
\hline & safety concerns & $\begin{array}{l}\text { E.g., R feels unsafe walking after dark; } \\
\text { "hassled by teenagers" }\end{array}$ \\
\hline & unspecified/other & E.g., "crime"; prostitution \\
\hline Homelessness & & $\begin{array}{l}\text { Concerns about people camping out nearby; } \\
\text { homeless people }\end{array}$ \\
\hline $\begin{array}{l}\text { Lack of access to } \\
\text { stores/services }\end{array}$ & & $\begin{array}{l}\text { Lack of wanted resources - shops, restaurants, } \\
\text { libraries, parks, health care; also includes } \\
\text { responses such as "boring" or "nothing to do" } \\
\text { which indicated late of entertainment nearby }\end{array}$ \\
\hline Litter & & $\begin{array}{l}\text { Presence of litter, trash, other unsightly dirt or } \\
\text { garbage; "dirty" }\end{array}$ \\
\hline Location & & $\begin{array}{l}\text { General location complaints, e.g., "too close to } \\
\text { city"; too far from friends/family }\end{array}$ \\
\hline \multirow[t]{3}{*}{ Noise pollution } & unspecified/other & $\begin{array}{l}\text { General noise complaints, e.g., "too loud"; } \\
\text { "noisy" }\end{array}$ \\
\hline & traffic & $\begin{array}{l}\text { Noise from street; emergency vehicles; garbage } \\
\text { trucks; etc. }\end{array}$ \\
\hline & neighbors & $\begin{array}{l}\text { Parties; loud arguments; children; barking } \\
\text { dogs; music }\end{array}$ \\
\hline $\begin{array}{l}\text { Physical } \\
\text { quality }\end{array}$ & & $\begin{array}{l}\text { E.g., poor quality or lack of sidewalks; lack of } \\
\text { streetlights }\end{array}$ \\
\hline Traffic & & $\begin{array}{l}\text { Unsafe streets; traffic accidents; lack of } \\
\text { parking; traffic noise coded as noise pollution- } \\
\text { traffic }\end{array}$ \\
\hline $\begin{array}{l}\text { Transportation } \\
\text { difficulties }\end{array}$ & & $\begin{array}{l}\text { E.g., infrequent bus service; distance from Max } \\
\text { or bus lines }\end{array}$ \\
\hline Other & & $\begin{array}{l}\text { All other responses: e.g., concerns about gossip } \\
\text { and privacy; individual phobias; solicitors; } \\
\text { stigma associated with housing }\end{array}$ \\
\hline None/nothing & & No response given; "nothing" \\
\hline
\end{tabular}


Table 9.

Codebookfor "Like” Responses.

\begin{tabular}{|c|c|c|}
\hline Theme & Subtheme & Description \\
\hline Ease of transportation & & $\begin{array}{l}\text { Close to public transportation; frequent bus } \\
\text { service; close to freeway }\end{array}$ \\
\hline Family atmosphere & & $\begin{array}{l}\text { "Neighborhood children"; "family oriented"; } \\
\text { "family atmosphere" }\end{array}$ \\
\hline Peace and quiet & & "Quiet"; "peaceful” \\
\hline Lack of traffic* & & $\begin{array}{l}\text { No busy streets; safe intersections; lack of } \\
\text { traffic-specific noise }\end{array}$ \\
\hline \multirow[t]{3}{*}{ Location } & $\begin{array}{l}\text { Location/access to } \\
\text { stores and services }\end{array}$ & $\begin{array}{l}\text { Close to shops, restaurants, health care; also } \\
\text { general location appreciation, including "close to } \\
\text { everything" and "location" }\end{array}$ \\
\hline & Proximity to family & Close to family \\
\hline & Proximity to park & Close to park; close to bike trail \\
\hline Physical quality & & Good sidewalks; repaired street lights \\
\hline Friendly neighbors & & $\begin{array}{l}\text { Neighbors are friendly; friends live in the } \\
\text { neighborhood; sense of community; friendly } \\
\text { atmosphere }\end{array}$ \\
\hline Safety & & Feels safe; no crime \\
\hline Appearance/cleanliness & & "Pretty"; "clean" \\
\hline Nature & & Nature; gardens; flowers; trees \\
\hline Proximity to park & & R specifically mentions park nearby \\
\hline Other & & $\begin{array}{l}\text { E.g., distal support; diversity; "familiar"; } \\
\text { "home"; "classy"; recovery focus }\end{array}$ \\
\hline None/nothing & & No response given; "nothing" \\
\hline
\end{tabular}


Table 10.

Results for "Dislike” Responses.

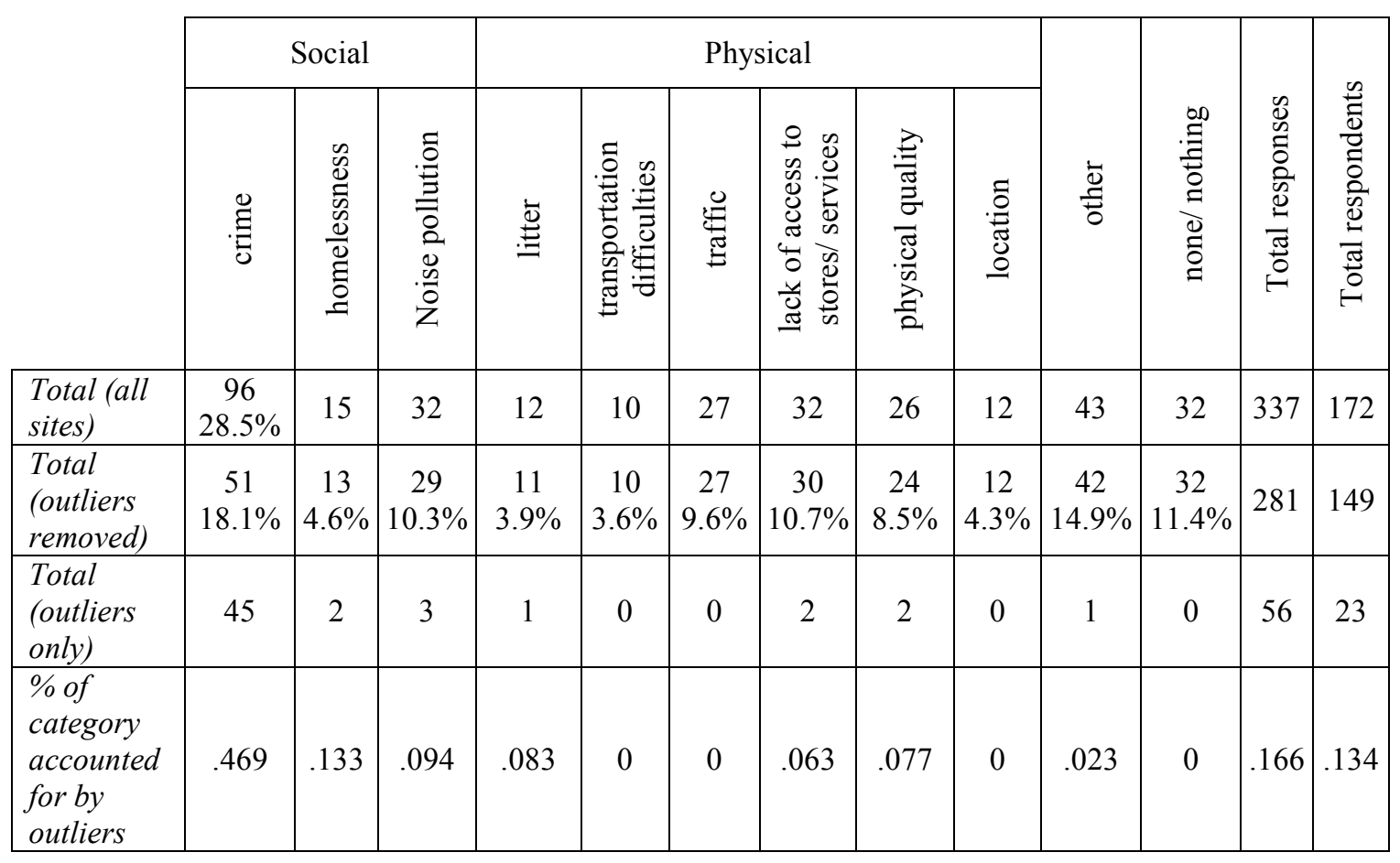

Table 10.1.

Crime breakdown.

\begin{tabular}{|l|c|c|c|c|c|c|c|}
\cline { 2 - 8 } \multicolumn{1}{c|}{} & $\begin{array}{c}\text { drug } \\
\text { use }\end{array}$ & gangs & $\begin{array}{c}\text { safety } \\
\text { concerns }\end{array}$ & violence & property & $\begin{array}{c}\text { unspecified/ } \\
\text { other }\end{array}$ & $\begin{array}{c}\text { Total all } \\
\text { crime }\end{array}$ \\
\hline Total (all sites) & 38 & 10 & 10 & 7 & 4 & 27 & 96 \\
\hline $\begin{array}{l}\text { Total (outliers } \\
\text { removed) }\end{array}$ & 19 & 2 & 7 & 3 & 3 & 17 & 51 \\
\hline Total (outliers only) & 19 & 8 & 3 & 4 & 1 & 10 & 45 \\
\hline $\begin{array}{l}\text { \% of category } \\
\text { accounted for by } \\
\text { outliers }\end{array}$ & .5 & .8 & .3 & .571 & .25 & .37 & .469 \\
\hline
\end{tabular}


Table 11.

Results for "Like" Responses.

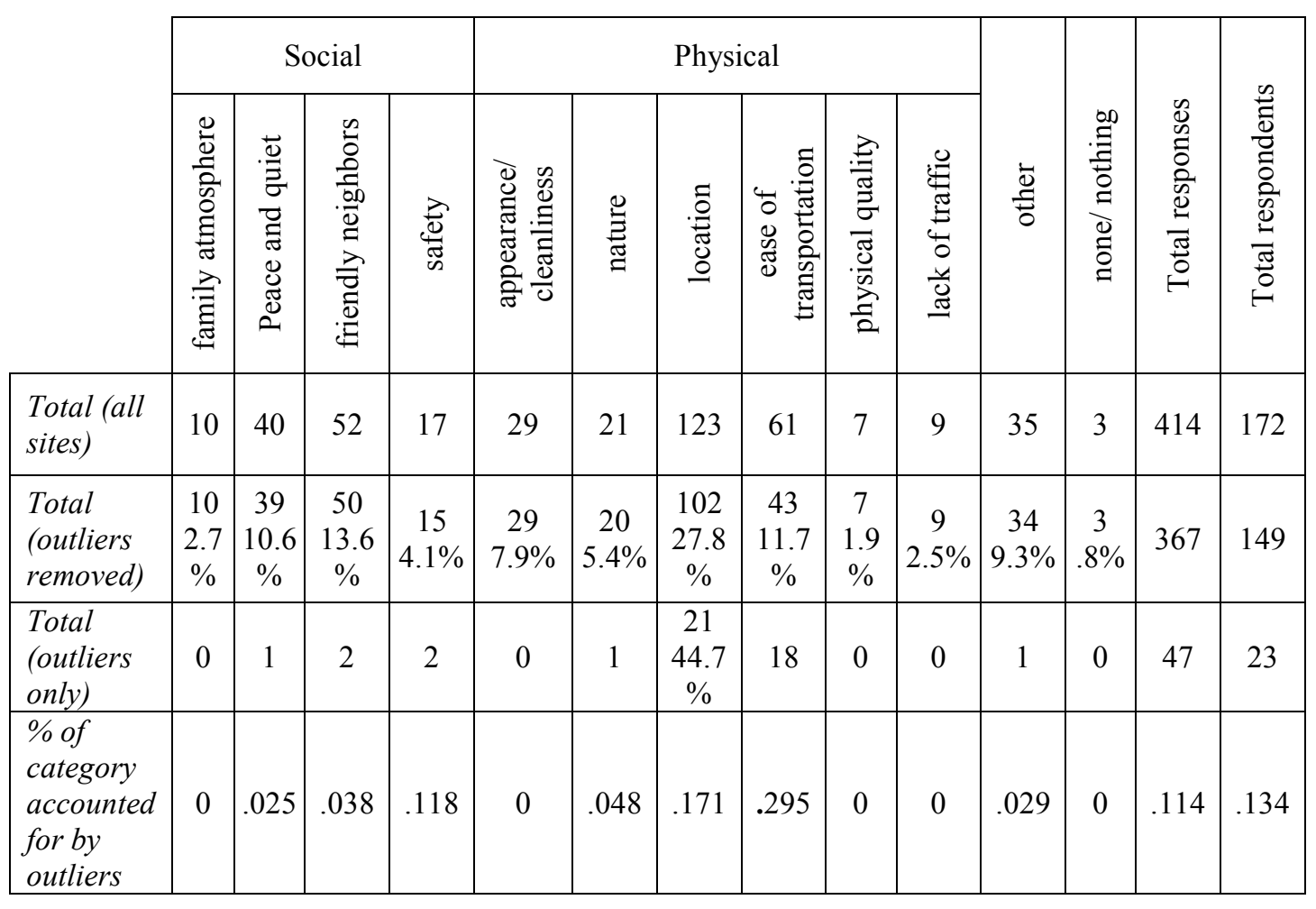


Table 11.1.

Location Breakdown.

\begin{tabular}{|c|c|c|c|c|}
\hline & $\begin{array}{c}\text { Access to } \\
\text { stores/services }\end{array}$ & $\begin{array}{l}\text { Proximity to } \\
\text { park }\end{array}$ & $\begin{array}{l}\text { Proximity to } \\
\text { family }\end{array}$ & $\begin{array}{l}\text { Total all } \\
\text { location }\end{array}$ \\
\hline Total (all sites) & $\begin{array}{c}102 \\
82.9 \%\end{array}$ & $\begin{array}{c}16 \\
13 \%\end{array}$ & $\begin{array}{c}5 \\
4.1 \% \\
\end{array}$ & 123 \\
\hline Total (outliers removed) & $\begin{array}{c}89 \\
87.3 \%\end{array}$ & $\begin{array}{c}9 \\
8.8 \%\end{array}$ & $\begin{array}{c}4 \\
3.9 \%\end{array}$ & 102 \\
\hline Total (outliers only) & $\begin{array}{c}13 \\
61.9 \%\end{array}$ & $\begin{array}{c}7 \\
33.3 \%\end{array}$ & $\begin{array}{c}1 \\
4.8 \%\end{array}$ & 21 \\
\hline $\begin{array}{l}\% \text { of category accounted } \\
\text { for by outliers }\end{array}$ & .127 & .438 & .2 & .171 \\
\hline
\end{tabular}




\section{Appendix III. Measures}

\section{Residential Satisfaction (HES-RS)}

I'd like to ask you some general questions about your living situation.

1. How satisfied are you with this neighborhood as a place to live?

\begin{tabular}{|l|l|l|l|l|}
\hline $\begin{array}{l}\text { Very } \\
\text { Dissatisfied }\end{array}$ & Dissatisfied & $\begin{array}{l}\text { Neither } \\
\text { Dissatisfied or } \\
\text { Satisfied }\end{array}$ & Satisfied & $\begin{array}{l}\text { Very } \\
\text { Satisfied }\end{array}$ \\
\hline 1 & 2 & 3 & 4 & 5 \\
\hline
\end{tabular}

2. How does your current neighborhood compare to your previous neighborhood?

\begin{tabular}{|l|l|l|}
\hline 1- Better & 2-Same & 3-Worse \\
\hline
\end{tabular}

Neighborhood Quality (HES-NQ)

For the next questions, I'll ask your opinion about different parts of your neighborhood.

Please tell me how much you agree or disagree with each statement.

\begin{tabular}{|c|c|c|c|c|c|}
\hline \multirow[b]{2}{*}{$\begin{array}{l}\text { 1. It is easy to get transportation in my } \\
\text { neighborhood }\end{array}$} & \multicolumn{5}{|c|}{$\begin{array}{l}1=\text { Strongly Disagree } \\
2=\text { Disagree } \\
3=\text { Neither Disagree or Agree } \\
4=\text { Agree } \\
5=\text { Strongly Agree }\end{array}$} \\
\hline & 1 & 2 & 3 & 4 & 5 \\
\hline 2. Crime is a problem in my neighborhood & 1 & 2 & 3 & 4 & 5 \\
\hline $\begin{array}{l}\text { 3. I can get the things that I need from stores in } \\
\text { my neighborhood (food, clothes, supplies) }\end{array}$ & 1 & 2 & 3 & 4 & 5 \\
\hline $\begin{array}{l}\text { 4. I have a hard time getting health care } \\
\text { services in my neighborhood }\end{array}$ & 1 & 2 & 3 & 4 & 5 \\
\hline $\begin{array}{l}\text { 5. There are things to do for fun in my } \\
\text { neighborhood (movie theatre, bowling) }\end{array}$ & 1 & 2 & 3 & 4 & 5 \\
\hline $\begin{array}{l}\text { 6. Police respond in a timely manner in this } \\
\text { neighborhood }\end{array}$ & 1 & 2 & 3 & 4 & 5 \\
\hline $\begin{array}{l}\text { 7. My family and friends are too far away from } \\
\text { where I live }\end{array}$ & 1 & 2 & 3 & 4 & 5 \\
\hline $\begin{array}{l}\text { 8. There are not enough street lights in my } \\
\text { neighborhood }\end{array}$ & 1 & 2 & 3 & 4 & 5 \\
\hline 9. My neighborhood looks nice & 1 & 2 & 3 & 4 & 5 \\
\hline $\begin{array}{l}\text { 10. There is too much noise in my } \\
\text { neighborhood }\end{array}$ & 1 & 2 & 3 & 4 & 5 \\
\hline 11. I have good sidewalks in my neighborhood & 1 & 2 & - & 7 & 5 \\
\hline $\begin{array}{l}\text { 12. There is a lot of traffic on the streets in my } \\
\text { neighborhood }\end{array}$ & 1 & 2 & 3 & 4 & 5 \\
\hline 13. There are nice parks in my neighborhood & 1 & 2 & 3 & 4 & 5 \\
\hline
\end{tabular}




\begin{tabular}{|l|lllll|}
\hline $\begin{array}{l}\text { 14. I can't do things outdoors in my } \\
\text { neighborhood }\end{array}$ & 1 & 2 & 3 & 4 & 5 \\
\hline
\end{tabular}

Neighborhood Social Climate (HES-NSC)

Okay, now I will ask about how much you AGREE or DISAGREE with the following statements about your neighborhood.

\begin{tabular}{|c|c|c|c|c|c|}
\hline & Agree & & $\begin{array}{l}\text { sag } \\
\text { ith }\end{array}$ & są & \\
\hline 1. I feel safe in my neighborhood. & 1 & 2 & 3 & 4 & 5 \\
\hline $\begin{array}{l}\text { 2. Sometimes I feel unwelcome in my } \\
\text { neighborhood because of my ethnicity and my } \\
\text { cultural background. }\end{array}$ & 1 & 2 & 3 & 4 & 5 \\
\hline $\begin{array}{l}\text { 3. People in my neighborhood are friendly to } \\
\text { everybody no matter what the person's skin } \\
\text { color or ethnic background. }\end{array}$ & 1 & 2 & 3 & 4 & 5 \\
\hline $\begin{array}{l}\text { 4. Police treat people differently in my } \\
\text { neighborhood because of the color of their skin. }\end{array}$ & 1 & 2 & 3 & 4 & 5 \\
\hline $\begin{array}{l}\text { 5. Sometimes, people in my neighborhood } \\
\text { hassle me when I'm out walking. }\end{array}$ & 1 & 2 & 3 & 4 & 5 \\
\hline $\begin{array}{l}\text { 6. I need to be careful who I talk to in my } \\
\text { neighborhood. }\end{array}$ & 1 & 2 & 3 & 4 & 5 \\
\hline 7. My neighborhood is an easy place to live. & 1 & 2 & 3 & 4 & 5 \\
\hline $\begin{array}{l}\text { 8. People in my neighborhood treat me as an } \\
\text { equal. }\end{array}$ & 1 & 2 & 3 & 4 & 5 \\
\hline $\begin{array}{l}\text { 9. Sometimes I feel unwelcome in my } \\
\text { neighborhood because of my mental illness. }\end{array}$ & 1 & 2 & 3 & 4 & 5 \\
\hline $\begin{array}{l}\text { 10. People in this neighborhood know that I } \\
\text { have a mental illness. }\end{array}$ & 1 & 2 & 3 & 4 & 5 \\
\hline $\begin{array}{l}\text { 11. Some people in my neighborhood give me } \\
\text { a hard time because of my mental illness. }\end{array}$ & 1 & 2 & 3 & 4 & 5 \\
\hline $\begin{array}{l}\text { 12. People in this neighborhood are afraid of } \\
\text { me because of my mental illness. }\end{array}$ & 1 & 2 & 3 & 4 & 5 \\
\hline
\end{tabular}




\section{Neighbor Scale (HES-N)}

For these next questions, how much you AGREE or DISAGREE with the following statements?

\begin{tabular}{|c|c|c|c|c|c|}
\hline \multirow[b]{2}{*}{ 1. I can count on a neighbor for help when I need it. } & \multicolumn{5}{|c|}{$\begin{array}{l}1=\text { Strongly Disagree } \\
2=\text { Disagree } \\
3=\text { Neither Disagree or } \\
\text { Agree } \\
4=\text { Agree } \\
5=\text { Strongly Agree }\end{array}$} \\
\hline & 1 & 2 & 3 & 4 & 5 \\
\hline $\begin{array}{l}\text { 2. There is no one in my neighborhood with whom I'm } \\
\text { close. }\end{array}$ & 1 & 2 & 3 & 4 & 5 \\
\hline $\begin{array}{l}\text { 3. I have a close relationship with a neighbor (not } \\
\text { necessarily a romantic relationship). }\end{array}$ & 1 & & 3 & 4 & 5 \\
\hline $\begin{array}{l}\text { 4. If I needed it, one of my neighbors would give me a } \\
\text { ride to an appointment. }\end{array}$ & 1 & 2 & 3 & 4 & 5 \\
\hline 5. My neighbors and I argue a lot. & 1 & 2 & 3 & 4 & 5 \\
\hline $\begin{array}{l}\text { 6. If I needed someone to talk to about a problem, I } \\
\text { could talk with one of my neighbors. }\end{array}$ & 1 & & 3 & 4 & 5 \\
\hline $\begin{array}{l}\text { 7. My neighbors keep an eye on my apartment when I } \\
\text { am gone. }\end{array}$ & 1 & 2 & 3 & 4 & 5 \\
\hline 8. My neighbors invite me to do things with them. & 1 & 2 & 3 & 4 & 5 \\
\hline 9. My neighbors complain about me or my apartment. & 1 & 2 & 3 & 4 & \\
\hline
\end{tabular}




\section{Neighborhood Safety (HES-S)}

Next I will ask about activity in your neighborhood. Please think about the area right outside of or in your building.

\begin{tabular}{|c|c|c|c|c|c|c|c|}
\hline & $\begin{array}{l}0 \\
1 \\
2 \\
3 \\
4 \\
5 \\
6\end{array}$ & & $\begin{array}{l}\mathrm{W} \\
3 \mathrm{~T} \\
\mathrm{ice} \\
3 \mathrm{~T} \\
\text { ice }\end{array}$ & $\begin{array}{l}\text { nes } \\
\text { r } \\
\text { es } \\
\mathrm{We} \\
\text { es } \\
\mathrm{Da}\end{array}$ & $\begin{array}{l}\text { Ye } \\
\text { ith } \\
\text { Ior }\end{array}$ & Le & \\
\hline $\begin{array}{l}\text { 1. How often are people attacked right around } \\
\text { your building? }\end{array}$ & 0 & 1 & 2 & 3 & 4 & 5 & 6 \\
\hline 2. How often are people selling drugs? & 0 & 1 & 2 & 3 & 4 & 5 & 6 \\
\hline 3. How often are people using drugs? & 0 & 1 & 2 & 3 & 4 & 5 & 6 \\
\hline $\begin{array}{l}\text { 4. How often are people robbed around your } \\
\text { building? }\end{array}$ & 0 & 1 & 2 & 3 & 4 & 5 & 6 \\
\hline $\begin{array}{l}\text { 5. How often have people had things stolen from } \\
\text { their apartment (place, home)? }\end{array}$ & 0 & 1 & 2 & 3 & 4 & 5 & 6 \\
\hline $\begin{array}{l}\text { 6. How often does destruction of property } \\
\text { happen? }\end{array}$ & 0 & 1 & 2 & 3 & 4 & 5 & 6 \\
\hline $\begin{array}{l}\text { 7. How often are groups of people just hanging } \\
\text { out and causing problems? }\end{array}$ & 0 & 1 & 2 & 5 & 4 & 5 & 6 \\
\hline $\begin{array}{l}\text { 8. How often does new graffiti appear (painting } \\
\text { or writing on walls)? }\end{array}$ & 0 & 1 & 2 & 3 & 4 & 5 & 6 \\
\hline 9. How often are weapons used (guns, knives)? & 0 & 1 & 2 & 3 & 4 & 5 & 6 \\
\hline
\end{tabular}




\section{Researcher-rated Neighborhood Quality (HERS-NQ)}

\section{General Description of Scale}

1. Non-functional, hazardous; this characteristic of the neighborhood cannot function as it should, and may pose a hazard to the inhabitants; it is a big problem

2. Minimally functional; this characteristic of the neighborhood barely functions as it should and does not pose a hazard, yet borders on adequate. This characteristic would function much better if repairs or changes were made; it is a problem.

3. Adequate; this characteristic of the neighborhood meets general standards, it functions as it is intended to, and does not pose a hazard. Repairs or changes may not drastically change the quality or functionality of this characteristic; it is not a problem nor an advantage.

4. More than adequate; this rating should be reserved for advantageous characteristics of the neighborhood that are perceived to enhance the quality of life. This is something that is much better than average.

Checklist Instructions: Place " $\mathrm{X}$ " for each of the characteristics that are present in the participant's living space. Place "O" for any characteristics not present so that they can be recorded as such, and not as a skip or as missing data. In some cases, n/a will be the appropriate response.

Neighborhood identification instructions: The area surrounding the participants' living space is defined as one block's distance in any 4 directions. This may encompass only the housing site or may extend beyond the boundaries of a given apartment building. These general guidelines will always apply, but specific instructions regarding the boundaries for the observation will be decided at the site and will be communicated to all observers before the ratings take place. Conduct the observations by walking or driving the designated areas for several minutes. Indicate $\mathrm{n} / \mathrm{a}$ in response cells if necessary; leave no answer blank.

Name/ Description of Neighborhood

\begin{tabular}{|l|}
\hline \multicolumn{2}{|l|}{ This area of this neighborhood appears to be (or can be characterized as)... } \\
CHECK ONE
\end{tabular}




\begin{tabular}{|c|}
\hline HERS-NQ Checklist \\
\hline $\begin{array}{l}\text { 1. Broken windows or other structural damage on structures other than } \\
\text { the participants' housing complex. }\end{array}$ \\
\hline 2. Poorly kept vacant lot or lots on participants' block \\
\hline 3. Overgrown, poorly kept lawns or other "green space" \\
\hline 4. Presence of tended gardens or shrubs \\
\hline 5. Presence of shaded areas where one can sit outside \\
\hline $\begin{array}{l}\text { 6. Usable yard accessible for research participant (as part of their housing } \\
\text { complex) }\end{array}$ \\
\hline 7. Uncollected trash \\
\hline 8. Debris in the gutters \\
\hline 9. Impassable sidewalk (cluttered, broken, etc.) \\
\hline 10. Signs of property destruction \\
\hline 11. Graffiti on buildings or other structures \\
\hline 12. Missing or damaged street signs \\
\hline 13. Abandoned cars (i.e. on blocks, rusting, appear to be unusable) \\
\hline 14. Loitering adults or youth \\
\hline 15. Evidence of drug use (include alcohol) \\
\hline 16. Stores that sell alcohol for off-premise consumption \\
\hline 17. A bus stop \\
\hline $\begin{array}{l}\text { 18. Nearby streets that are unsafe for a pedestrian to cross due to heavy } \\
\text { and/or fast traffic }\end{array}$ \\
\hline
\end{tabular}

\begin{tabular}{|l|l|}
\hline \multicolumn{2}{|c|}{$\begin{array}{c}\text { 19. In relation to the other structures in the block area, how does the } \\
\text { participant's housing complex/site compare? CHECK ONE }\end{array}$} \\
\hline & Poor quality in relation to other structures \\
\hline Very similar quality in relation to other structures \\
\hline High quality in relation to other structures \\
\hline
\end{tabular}

\begin{tabular}{|c|c|c|c|}
\hline \multicolumn{4}{|c|}{ HERS-NQ Adequacy Ratings } \\
\hline $\begin{array}{c}\text { Non-functional / } \\
\text { hazardous }\end{array}$ & $\begin{array}{c}\text { Minimally } \\
\text { Functional }\end{array}$ & Adequate & More than adequate \\
\hline 1 & 2 & 3 & 4 \\
\hline
\end{tabular}




\begin{tabular}{|c|c|c|c|}
\hline $\begin{array}{l}\text { 20. Rate the quality of the structures in this block area. } \\
\text { (condition of foundation, peeling paint, structural damage) }\end{array}$ & 1 & 2 & 4 \\
\hline $\begin{array}{l}\text { 21. Rate the quality of public spaces in this block area. } \\
\text { (space is poorly or well-kept-such as landscaping, } \\
\text { gardening-for the types of activity the space appears to } \\
\text { intended) }\end{array}$ & 1 & 2 & 4 \\
\hline $\begin{array}{l}\text { 22. Can tenants clearly use the public spaces in the } \\
\text { block area? }\end{array}$ & Yes & Maybe & No \\
\hline \multicolumn{4}{|c|}{$\begin{array}{l}\text { 23. Additional comments on condition of the neighborhood: (In particular, please } \\
\text { describe any salient hazardous or enhancing ratings given. }\end{array}$} \\
\hline \multicolumn{4}{|c|}{$\begin{array}{l}\text { HERS-NQ: Please answer the following questions based on what you can conclude about } \\
\text { the community surrounding the housing site by walking or driving the designated areas. } \\
\text { CIRCLE ONE }\end{array}$} \\
\hline $\begin{array}{l}\text { 24. Is this housing site physically integrated with other } \\
\text { areas? (regarding ease of accessibility to other nearby } \\
\text { residential areas) }\end{array}$ & Yes & Maybe & No \\
\hline $\begin{array}{l}\text { 25. Do stores and services appear to be within walking } \\
\text { distance? (a few minutes' walk) }\end{array}$ & Yes & Maybe & No \\
\hline $\begin{array}{l}\text { 26. Is there access to other areas of the community by } \\
\text { walking? (take into account safety, physical barriers that } \\
\text { isolate this area and proximity, defined as less than } 10 \\
\text { minutes' walk) }\end{array}$ & Yes & Maybe & No \\
\hline \multicolumn{4}{|c|}{$\begin{array}{l}\text { 27. Additional comments on the relative integration or isolation of this neighborhood } \\
\text { with the surrounding community: }\end{array}$} \\
\hline
\end{tabular}

\section{Qualitative Questions.}

1. What are three things you like about your neighborhood?

2. What are three things you don't like about your neighborhood? 